\title{
Coastal plankton responses to turbulent mixing in experimental ecosystems
}

\author{
John E. Petersen*, Lawrence P. Sanford, W. Michael Kemp \\ Horn Point Laboratory, University of Maryland Center for Environmental Science, Cambridge, Maryland 21613, USA
}

\begin{abstract}
Turbulent mixing is increasingly implicated as a key factor regulating ecological dynamics in coastal planktonic systems. Although photosynthesis is directly fueled by light energy, it has been hypothesized that the 'auxiliary' energy provided by mixing can subsidize or control ecosystem function. Unrealistic mixing has also been cited as one explanation for difficulties in reproducing natural plankton dynamics in enclosed experimental ecosystems (mesocosms). To explore the importance of mixing in shallow planktonic ecosystems, we traced changes over a 4 wk period in population, community, and ecosystem level properties in replicate $1 \mathrm{~m}^{3}$ experimental ecosystems subjected to different mixing regimes. Mixing energy was delivered by slowly rotating impellers on a cycle of $4 \mathrm{~h}$ on and $2 \mathrm{~h}$ off to match the semidiurnal pattern of tidal mixing that characterizes many temperate estuaries. Three mixing levels were generated by altering impeller rotation rates. The intermediate level was scaled to match typical mixing intensities of waters in Chesapeake Bay, the low mixing level approximated calm oceanic surface waters, and the high mixing level approximated the environment within a tidal front. High and low mixing levels encompassed a $6 \times$ range in turbulence intensity, a $9 \times$ range in the surface-bottom mixing time and eddy diffusivity coefficients, and a $230 \times$ range in turbulent energy dissipation rates. Mixing had a significant negative effect on copepod and gelatinous zooplankton abundance and also altered the timing of peak copepod densities. Chlorophyll a dynamics and phytoplankton group composition, as assessed with accessory pigment concentrations, also exhibited modest differences among mixing treatments. Mixing had negligible effects on nutrient concentrations and on community and whole-system productivity and respiration. Important caveats in interpreting the results of this experiment are that system size excluded observation of the effects of large-scale mixing processes, trophic complexity was limited (e.g. no fish), and in this whole-ecosystem context it was difficult to distinguish direct from indirect effects of mixing. Nevertheless, our results imply that ecosystem-level processes in planktonic systems may often be less sensitive to differences in small-scale turbulence than population and community dynamics, and also that mixing effects may be strongly dependent on the specific structure of particular ecosystems.
\end{abstract}

KEY WORDS: Mixing Turbulence Plankton - Copepod Mesocosm . Production - Respiration · Auxiliary energy

'Even the relatively small flows of physical energy from the wind and the tide set in motion a cascade of eddies and ecological effects that can alter dramatically the much larger flows of solar and chemical energy.'

(Nixon 1988)

\section{INTRODUCTION}

A considerable fraction of the energy embodied in waves and tides is dissipated in the coastal zone (Miller 1966), and as a result turbulent mixing is generally

•E-mail: petersen@hpl.umces.edu enhanced in nearshore ecosystems relative to lakes and the deep ocean (Nixon 1988, Howarth et al. 1993). This turbulent mixing is increasingly implicated as a key factor regulating ecological dynamics at population, community, and ecosystem levels of organization. In situ study of turbulence effects in planktonic communities pases considerable methodological challenges. Specifically, advection, local variability, and the difficulty of accurately characterizing turbulence in nature lead most plankton researchers interested in turbulence effects to seek more controlled environments. Although single and multi-species cultures provide useful tools for evaluating certain population and 
Table 1. Empirically determined effects of mixing on phytoplankton, zooplankton, and ecosystem processes. ( + ) indicates a positive relationship between the variable and turbulence, (-) indicates a negative relationship, ( $v$ ) indicates the presence of a relationship, $(0)$ indicates no relationship. In some cases the same reference may be cited for both + and - effects, indicating that the direction of the relationship depends on degree or other factors. Because mixing levels used in individual experiments ranged from no mixing to levels atypical of nature, this table can only be consıdered a very rough summary of findings

\begin{tabular}{|c|c|c|}
\hline & Variable & Relationship/reference \\
\hline Phytoplankton & $\begin{array}{l}\text { Settlıng rate } \\
\text { Cell size } \\
\text { Cell abundance } \\
\text { Chlorophyll a } \\
\text { Cell growth } \\
\text { Diatom/flagellate } \\
\text { Species composition } \\
\text { Nutrient uptake } \\
\text { Timing of bloom }\end{array}$ & $\begin{array}{l}\text { (-) } 5,6,8,16,18,34,38 \\
\text { (+) } 6,8,33,35 \\
\text { (+) } 1,4,19,22 ;(0) 19 \\
\text { (+) } 9,19,20,22 \\
\text { (+) } 11,13,31 ;(-) 11,13,37 \\
\text { (+) } 6,8,9,10,14,20,35 \\
\text { (v) } 8,10,13,24,25,36,38 ;(0) 19 \\
\text { (+) } 21,31 ;(-) 31 . \\
\text { (v) } 1,9,20,31\end{array}$ \\
\hline Microzooplankton (protozoa) & $\begin{array}{l}\text { Predation/grazing rate } \\
\text { Growth rate (numbers) } \\
\text { Cell size }\end{array}$ & $\begin{array}{l}\text { (t) } 23,32 ;(-) 32 ;(0) 32 \\
\text { (+) } 23 \\
(-) 23\end{array}$ \\
\hline Mesozooplankton (copepods) & $\begin{array}{l}\text { Abundance/biomass } \\
\text { Metabolic rate } \\
\text { Excretion rate } \\
\text { Predation/grazing rate } \\
\text { Growth rate } \\
\text { Development rate } \\
\text { Age structure } \\
\text { Sex ratio }\end{array}$ & $\begin{array}{l}\text { (-) } 1,4,19,20,22 ;(+) 22 \\
\text { (t) } 1,2,3,27,29 \\
\text { (+) } 1,28 \\
\text { (+) } 27,29,30 ;(-) 1,27,30,33 \\
\text { (+) } 26 \\
\text { (+) } 26 \\
\text { (v) } 1,19,26 \\
\text { (v) } 1\end{array}$ \\
\hline Ecosystem & $\begin{array}{l}\text { Community productivity } \\
\text { Ecosystem productivity } \\
\text { Ecosystem } \mathrm{R} \\
\text { Nutrient dynamics }\end{array}$ & $\begin{array}{l}(+) 7,12,17,22^{b} ;(-) 17 ;(0) 12,15^{b} \\
(+) 20 \\
(+) 20 \\
(\sqrt{b}) 10,18,20\end{array}$ \\
\hline \multicolumn{3}{|c|}{$\begin{array}{l}\text { 'The category 'community productivity' includes standard bottle incubation experiments } \\
\text { 'These incubations were conducted with water that was taken from systems with different mixing regimes, but the incuba- } \\
\text { tions themselves were conducted under identical mixing levels }\end{array}$} \\
\hline \multicolumn{3}{|c|}{ 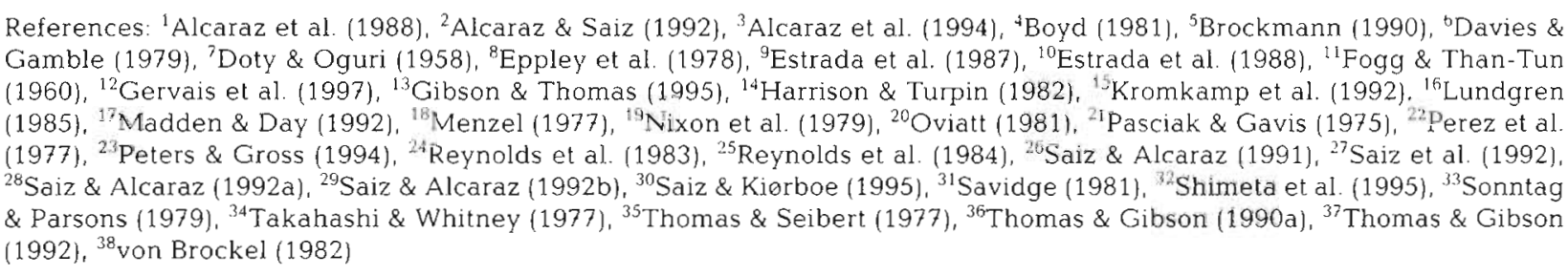 } \\
\hline
\end{tabular}

community level questions, one might expect enclosed experimental ecosystems ('mesocosms') to provide a more realistic environment in which to explore community and ecosystem level responses under replicated, controlled and repeatable conditions (Kemp et al. 1980, Odum 1984).

Previous experimental studies have revealed a variety of mixing effects on phytoplankton and zooplankton dynamics (Table 1). Within the phytoplankton community, positive relationships have been observed between the intensity of small-scale turbulence and cell size, cell abundance, chlorophyll a concentration, the ratio of diatoms to flagellates, and nutrient uptake rates (see Table 1 for references to experiments that support statements in this paragraph). Phytoplankton species composition, growth rate and the timing of bloom events have also been experimentally linked to turbulence. Experiments with copepods indicate a positive relationship between the degree of small-scale turbulence and metabolic rate, and a negative relationship between turbulence and abundance and biomass. Demographic characteristics of copepods, such as sex ratios and age structure, have also been linked to turbulence.

Theoretical and empirical work indicate that turbulence increases particle contact rates and therefore might be expected to enhance zooplankton feeding (Rothschild \& Osborn 1988, Mackenzie \& Leggett 1991. Hill et al. 1992). However, the effects of mixing on feeding depend on a number of other factors including zooplankton size, means of motility, and mode of feeding (Saiz et al. 1992, Kiørboe \& Saiz 1995). Gelati- 
nous zooplankton are known to be damaged by high degrees of turbulence (Acuna et al. 1994) and have been observed to avoid turbulence in nature (Harbison 1992).

At the ecosystem level it has been speculated that mixing provides an 'auxiliary' source of energy (sensu Odum 1967) that subsidizes direct solar input, and is in part responsible for the relatively high productivity of coastal ecosystems (Margalef 1978, Nixon 1988, Mann 1992). The actual effects of large- and small-scale mixing clearly depend on complex interactions between organism physiology and behavior, nutrient dynamics, and the light environment (Fig. 1, Table 1). On one hand, increased mixing has the potential to increase primary productivity by maintaining cells in the photic zone (Eppley et al. 1978; 'a' in Fig. 1), increasing phytoplankton access to benthic nutrients (Mann 1992; ' $C$ ' in Fig. 1), decreasing the diffusion gradient around cells (Lazier \& Mann 1989; ' $c$ ' in Fig. 1), decreasing copepod grazing (Alcaraz et al. 1988; 'b' in Fig. 1), and by increasing copepod excretion rates (Saiz \& Alcaraz 1992a; 'd' in Fig. 1). On the other hand, increased mixing also has the potential to decrease primary productivity by increasing grazing pressure (Saiz \& Alcaraz 1992b; 'b' in Fig. 1) and by increasing the turbidity due to sediment resuspension (' $\mathrm{a}$ ' in Fig. 1). In addition, although large-scale vertical mixing can replenish nutrient supply to surface waters (' $c$ ' in Fig. 1), it can also mix cells into aphotic waters, disrupting the necessary positive balance between photosynthesis and respiration (Sverdrup 1953; 'a' in Fig. 1). Ecosystem productivity and respiration reflect the outcome of these positive and negative effects of mixing. Few empirical studies have been conducted to quantitatively assess ecosystem level responses of plankton to the addition of mixing energy (Oviatt 1981, Kiørboe \& Saiz 1995, Gervais et al. 1997).

Although mesocosms have become widely used and accepted tools for exploring a wide variety of ecological questions (Ives et al. 1996), water column mixing has often been neglected in experimental design (Sanford 1997). A recent review of 360 aquatic mesocosm studies revealed that only $56 \%$ included some form of mechanical mixing (Petersen et al. in press). Few of those studies that have included mixing have also attempted to quantify turbulence with standard physical parameters that would allow for inter-experiment comparison (Savidge 1981, Thomas \& Gibson 1990a, Howarth et al. 1993), and fewer still have made an effort to quantitatively simulate or compare conditions between experimental and natural ecosystems (Gust 1977, Perez et al. 1977, Nixon et al. 1980). While turbulence levels in unmixed systems are typically low relative to nature (Verduin 1969, Steele et al. 1977, Davies \& Gamble 1979), turbulence levels are quite often

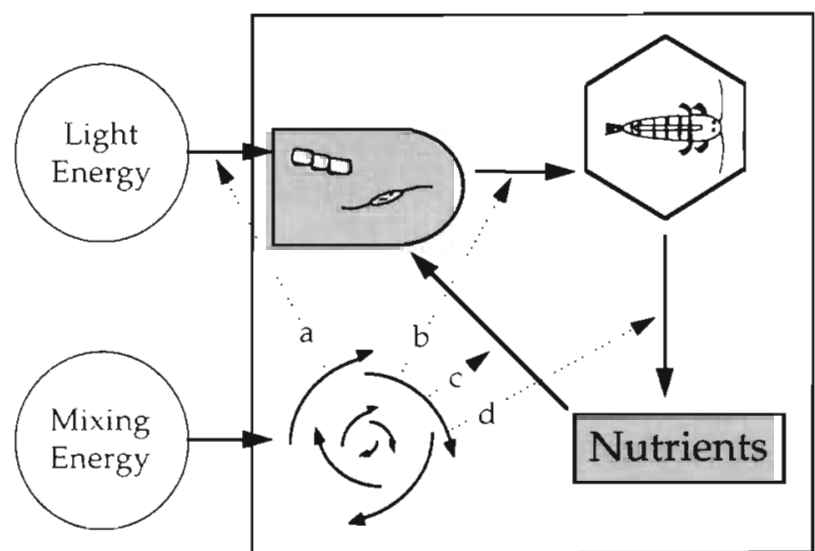

Fig. 1. Conceptual model of potential effects of mixing on primary productivity in a coastal planktonic ecosystem. Largescale vertical mixing processes control (a) light exposure and (c) the supply of nutrients from bottom waters. Small-scale turbulence influences copepod (b) feeding and (d) excretion. Small-scale turbulence also controls (c) diffusive flux of nutrients and wastes to and from planktonic cells. The 'bullet' shape represents phytoplankton and the hexagon represents planktonic consumers

unrealistically high in mechanically mixed systems (Sonntag \& Parsons 1979, Mann \& Lazier 1996, Peters $\&$ Redondo 1997). In either case, deficiencies in mixing may help explain discrepancies in behavior between experimental and natural ecosystems (Verduin 1969, Oviatt 1981, Bloesch et al. 1988). Although the challenge of quantifying turbulence has been cited as a serious obstacle to both experimentation and extrapolation (Estrada et al. 1987, Saiz et al. 1992), the necessary theoretical and empirical tools are increasingly available (Peters \& Redondo 1997, Sanford 1997). Thus, the important goal of experimentally quantifying relationships between planktonic processes and mixing is increasingly possible. The objective of this study was to determine if population, community, and ecosystem level processes could be quantitatively scaled as functions of mixing energy input.

\section{MATERIALS AND METHODS}

Experimental systems. The experimental system consisted of 9 cylindrical, $1.0 \mathrm{~m}$ deep, $1.0 \mathrm{~m}^{3}$ mesocosms constructed of Sun-Lite ${ }^{\infty}$, a fiberglass reinforced glazing material. Light was delivered from banks of broad-spectrum fluorescent bulbs on a cycle of $12 \mathrm{~h}$ light: $12 \mathrm{~h}$ dark. Average surface light intensity was $152 \mu \mathrm{E} \mathrm{m}^{-2} \mathrm{~s}{ }^{1}$. Mesocosms were insulated on the sides with silver faced bubble wrap to minimize transfer of heat and light through the walls. All tanks were housed in the same climate regulated room, and water temperature in all tanks remained at $23 \pm 0.5^{\circ} \mathrm{C}$ during 


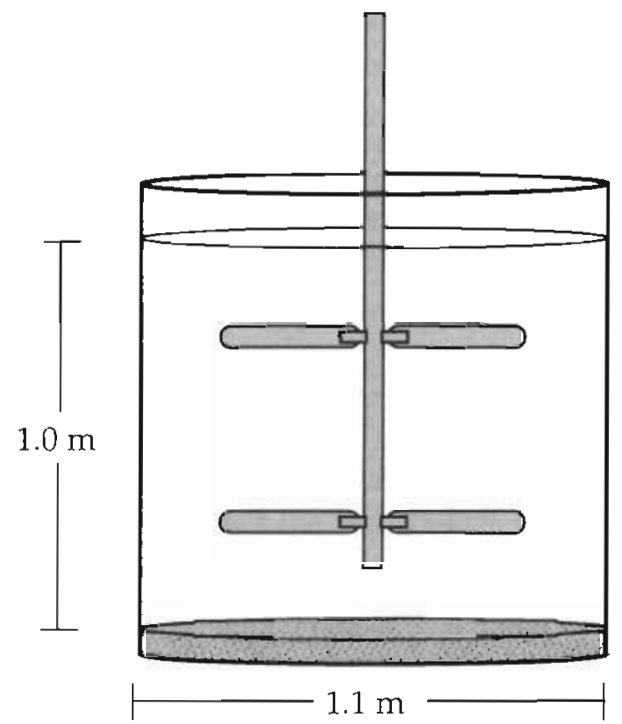

Fig. 2. Diagram of experimental ecosystem with mixing $\mathrm{Lm}$ peller

the experiment. Mixing in each tank was provided by means of 2 PVC impellers mounted on a vertical shaft that extended down into the center of the tank (Fig. 2). Impeller blades were located at depths of 25 and $75 \mathrm{~cm}$ from the surface, extended $28 \mathrm{~cm}$ from the center of the shaft, had widths of $8 \mathrm{~cm}$, and were held at a $45^{\circ}$ angle to the water surface. The impellers in each group of 3 replicate tanks were driven by a separate overhead motor linked to replicate tanks by gear boxes. To prevent the development of plug flow, impellers were programmed to rotate in one direction for 7.5 revolutions, stop for $15 \mathrm{~s}$ and then rotate in the opposite direction for 7.5 revolutions. In all treatments, mixing was on for $4 \mathrm{~h}$ and off for $2 \mathrm{~h}$ to simulate temporal variation in mixing intensity associated with the semidiurnal tidal activity that characterizes most temperate estuaries. High, intermediate and low mixing levels were generated by selecting impeller rotation rates of 9.9 , 3.75 and $1.2 \mathrm{rpm}$ respectively.
A variety of parameters was used to characterize mixing in the experimental ecosystems (Table 2). Prior to this experiment, 4 independent empirical methods were used to quantify mixing (Sanford 1997, Sanford et al. unpubl.). In one method, gypsum balls were deployed at various depths and distances from impellers, and dissolution rates $\left(R_{\mathrm{d}}\right)$ were determined. In a second method, turbulence velocities were measured directly with an acoustic Doppler velocimeter at several gypsum ball locations (Sontek Inc.). Turbulence intensity $(q)$ and turbulent energy dissipation rate $(\varepsilon)$ were calculated from these velocity measurements (see Sanford 1997 for equations). These values were then used to calibrate the gypsum dissolution technique so that overall distributions and volume weighted averages of $R_{\mathrm{d}} q$ and $\varepsilon$ could be calculated. In a third method, rhodamine dye was injected at the surface and bottom of mesocosms, and the time necessary to achieve a uniform distribution was taken as a measure of vertical mixing time $\left(T_{\mathrm{m}}\right)$. Vertical eddy diffusivity $\left(K_{z}\right)$ was calculated as $z^{2} /\left(2 T_{\mathrm{m}}\right)$, where $z=$ depth (Sanford 1997). In the final method, tanks were filled with tap water, sparged with nitrogen gas, and the rate of reoxygenation was measured to derive an air-water exchange coefficient $\left(K_{\mathrm{O}_{2}}\right.$; Petersen et al. 1997). Each of these methods was repeated at several different rotation rates so that empirical relationships between impeller rpm and the mixing parameter could be established. No effort was made to generate realistic mixing at the sediment water interface, and bottom shear was considerably lower than that found in nature.

The 3 mixing levels were selected so as to remain within the range of environmental conditions commonly experienced in planktonic ecosystems in nature (Peters \& Redondo 1997, Sanford 1997; Table 3). The intermediate mixing level was selected to roughly match conditions in surface waters of the Choptank River, a tributary of the Chesapeake Bay. The high mixing level was closer to conditions experienced by plankton in tidal fronts (e.g. Kiørboe \& Saiz 1995) and

Table 2 Mixing parameter definitions and values (volume-weighted averages) in low, intermediate, and high mixing treatments. Munimum/maximum is provided as a measure of the relative range between high and low values

\begin{tabular}{|c|c|c|c|c|c|}
\hline \multirow[t]{2}{*}{ Parameter } & \multirow[t]{2}{*}{ Symbol (units) } & \multicolumn{4}{|c|}{ Parameter values } \\
\hline & & Low & Intermediate & High & $\operatorname{Min} / \operatorname{Max}$ \\
\hline Impeller rotation rate & $\mathrm{rpm}\left(\mathrm{cycles} \mathrm{min}^{-1}\right)$ & 1.2 & 3.75 & 9.9 & 0.12 \\
\hline Surface-bottom mixing time & $T_{m}(\min )$ & 33.9 & 10.3 & 3.7 & 0.11 \\
\hline Vertical eddy diffusivity & $K_{z}\left(\mathrm{~cm}^{2} \mathrm{~s}^{-1}\right)$ & 2.5 & 8.1 & 22.6 & 0.11 \\
\hline Turbulent energy dissipation. & $\varepsilon\left(\mathrm{cm}^{2} \mathrm{~s}^{-3}\right)$ & 0.003 & 0.054 & 0.689 & 0.004 \\
\hline Gypsum dissolution rate & $R_{d}\left(\mathrm{~g} \mathrm{~h}^{-1}\right)$ & 8.4 & 12.6 & 22.5 & 0.38 \\
\hline Turbulence intensity & $q\left(\mathrm{~cm} \mathrm{~s}^{-1}\right)$ & 0.4 & 0.9 & 2.3 & 0.18 \\
\hline Oxygen diffusion coefficient & $K_{\mathrm{O}_{2}}\left(\mathrm{~cm} \mathrm{~h}^{-1}\right)$ & 0.7 & 1.4 & 2.9 & 0.25 \\
\hline
\end{tabular}


A 30 d experiment was conducted in the summer of 1995 (July 25 to August 23). Initial conditions included sediments $(10 \mathrm{~cm}$ depth) composed of a mixture of commercial sand and mud (1\% organic matter after mixing) and unfiltered water from Chesapeake Bay. Prior to the experiment, sediments were allowed to go anaerobic to reduce the abundance of benthic macrofauna and thereby reduce both benthic activity and the potential for heterogeneity among replicates. Mesocosms were incrementally filled with both sediments and water in order to minimize heterogeneity among tanks. Polychaete worms, and macrozooplankton such as gelatinous zooplankton polyps and copepods, entered the system in the sediments and the initial fill water, however, fish and other large predators were intentionally excluded. Previous experiments have indicated that complete closure to exchange significantly reduces biological activity (Petersen unpubl.). Therefore, $10 \%$ of the water in each mesocosm was drained on a daily basis and replaced with $0.5 \mu \mathrm{m}$ filtered estuarine water (intake salinity ranged from 9 to 12 psu). Mesocosm walls and impellers were scrubbed once per week throughout the experiment to minimize periphyton growth. A nutrient pulse was administered to all tanks at mid-experiment: on Day 13, silica was added to raise concentrations up to $30 \mu \mathrm{M}$, and on Day 14 concentrations of $\mathrm{NH}_{4}$ were increased to $25 \mu \mathrm{M}$ and concentrations of $\mathrm{PO}_{4}$ were increased to $1.6 \mu \mathrm{M}$ to maintain Redfield proportion (Redfield et al. 1963).

Variables assessed. Rates of whole-ecosystem primary productivity and respiration were measured by tracing changes in dissolved oxygen over time (Odum 1956. Welch 1968). Each mesocosm was equipped with a galvanic oxygen probe (OxyGuard stationary probe, Birkerød, Denmark) and continuous oxygen data were logged as averages over consecutive 5 min intervals. Probes were calibrated twice per week with air-saturated water and also with periodic Winkler titrations (Carritt \& Carpenter 1966). Dissolved oxygen exhibited approximately linear increases and decreases during light and dark periods, respectively.

Whole-ecosystem net primary productivity (NFP) was calculated as the average rate of change in dissolved oxygen during each light period. Similarly, whole-ecosystem respiration $(R)$ was calculated as the average rate of change during each dark period (a positive value for $R$ indicates a decrease in dissolved oxygen). Gross primary productivity $(G P P)$ was operationally defined as the sum of NPP and $R$. These metabolic measures were adjusted to account for the exchange of oxygen across the air-water interface using the formula $F=K_{\mathrm{O}_{2}} \mathrm{~S}$, where $\mathrm{F}$ is the rate of $\mathrm{O}_{2}$ diffusion $\left(\mathrm{g} \mathrm{O}_{2} \mathrm{~m}^{-2} \mathrm{~h}^{-1}\right), K_{\mathrm{O}_{2}}$ is the empirically derived oxygen air-water exchange coefficient $\left(\mathrm{m} \mathrm{h}^{-1}\right)$ for each mixing level (Table 2), and $S$ is the saturation deficit ( $g$ $\mathrm{O}_{2} \mathrm{~m}^{-3}$ ), or difference between dissolved oxygen concentration and saturated oxygen concentration at the appropriate temperature and salinity. Saturated $\mathrm{O}_{2}$ concentrations were calculated using published empirical relations (Benson \& Krause 1984).

In addition to these measures of total ecosystem metabolism, specially designed incubation chambers (Petersen \& Chen unpubl.) were used to partition the metabolic activity of the water column, wall periphyton, and benthic communities. The translucent incubation tubes that extended the full depth of the water column were constructed in pairs. Tubes contained mechanical mixing devices to prevent stratification and roughly simulate mixing in the intermediate level mixing regime; the mixing apparatus in incubation tubes was not adjusted to simulate mixing in each of the mixing treatments. Strips of $1.6 \mathrm{~cm}$ wide wall material extending the full depth of the mesocosms were attached to the sides of the mesocosms at the start of the experiment as a substrate for wall growth (Chen et al. 1997). These strips were periodically removed and incubated in one of the chambers with water column water. The other tube in the pair was incubated with water alone. Relatively constant rates of change in $\mathrm{O}_{2}$ enabled us to characterize metabolic activity with measures of $\mathrm{O}_{2}$ taken at 2 points during the light period and 1 point during the dark period. Incubations typically lasted about $12 \mathrm{~h}$ total. Wall periphyton net primary productivity was calculated by subtracting $N P P$ in the tube with water column water alone i.e. $N P P_{c}$ ) from $N P P$ in the tube with both water column and wall material. The value obtained was then divided by the area of the wall strip, multiplied by total wall area, and divided by mesocosm volume to obtain a rate per unit volume $\left(N P P_{p}\right)$ that could be compared with water column productivity. Respiration was calculated in a similar manner for data collected during the dark period. Incubations were conducted in each tank on Days 2, 9, 16, and 23 of the experiment.

The biomass and taxonomic composition of algal communities were assessed by tracing changes in chlorophyll a (chl a) and accessory pigments. Daily measures of water column chl a were made with in situ fluorometry (Wet Labs model 9602004) calibrated daily with in vitro fluorometry (Turner Designs model 10 series) following extraction with $90 \%$ acetone. Concentrations of chl a in the wall periphyton community were assessed on Day 10 and Day 17, immediately prior to cleaning by scraping material from wall strips. Scraped material was extracted in $90 \%$ acetone, sonicated to aid in pigment extraction, and assessed fluorometrically (Chen et al. 1997). In a fashion analogous to the calculation of wall periphyton productivity, the chl a value obtained was divided by the area of the 
wall strip, multiplied by total wall area and divided by volume to obtain a concentration expressed per unit volume of the tank so as to be comparable with water column chl a.

Accessory pigment composition was used to assess changes and differences in the taxonomic composition of the phytoplankton community. Water column samples were collected and analyzed with high precision liquid chromatography (Van Heukelem et al, 1994) at the beginning (Day 1), middle (Day 14), and end (Day 28) of the experiment. Pigments analyzed and known to be characteristic of phytoplankton groups (in parentheses) present within the Chesapeake Bay included alloxanthin (cryptophytes), fucoxanthin (chrysophytes and diatoms), lutein (chlorophytes), peridinin (chlorophytes), zeaxanthin (cyanobacteria), and violaxanthin (chlorophytes, see Rowan 1989, Marshall 1994).

Concentrations of dissolved inorganic nitrogen (DIN $=\mathrm{NH}_{4}+\mathrm{NO}_{3}+\mathrm{NO}_{2}$ ), dissolved inorganic phosphorus $\left(\mathrm{PO}_{4}\right)$, and dissolved silica ( $\mathrm{Si}$ ) were measured twice weekly in each of the experimental ecosystems. Water was removed from the center of each mesocosm by means of a siphoning tube, samples were filtered, and standard automated wet chemical methods were used to measure nutrient concentrations (Parsons et al. 1984: Autoanalyzer 2, Technicon Inc.).

A small gelatinous zooplankton, Moerisia lyonsii, a hydromedusa with a diameter of 0.5 to $5.1 \mathrm{~mm}$, only became apparent during the last week of the experiment and quantitative samples were collected on Days 25 and 28. Between 20 and $40 \mathrm{l}$ of water was removed from mid-depth in each mesocosm and $M$. lyonsii abundance was enumerated under a dissecting microscope. Copepod Acartia tonsa abundance was assessed twice weekly during the experiment with an optical plankton counter (OPC-Focal Technologies) calibrated with microscopic identification. Data for copepods ranging in length from 200 to $1000 \mu \mathrm{m}$ were segregated into eight $100 \mu \mathrm{m}$ size classes. Copepods in the 200 to $500 \mu \mathrm{m}$ range were operationally defined as juveniles; those in the 500 to $1000 \mu \mathrm{m}$ range were considered adults. Copepod biomass was calculated from lengths by applying the empirically derived equation (Heinle 1966) $W=10^{0.000865 \times L}$, where $W=$ dry weight $(\mu \mathrm{g})$ and $L=$ median length $(\mu \mathrm{m})$ for a given size class of $A$. tonsa. The total biomass in each size class was obtained by multiplying $W$ by abundance, and total biomass was taken as the sum of the individual size classes. A factor of $0.4 \mu \mathrm{g} \mu \mathrm{g}^{-1}$ was used to convert dry weight $(W)$ to carbon $\left(W_{c}\right)$. A second empirical equation (Hirst \& Sheader 1997) was used to roughly estimate the growth rates of the copepods. Since this equation does not consider the direct effects of mixing on copepod feeding (there is no eas- ily applicable equation that does, but see Table 1), we will refer to derived estimates as 'potential growth' and 'potential feeding'. For a constant temperature of $23^{\circ} \mathrm{C}$ this equation simplifies to $G=0.269 W_{c}^{-0.29 b 2}$, where $G=$ the biomass specific growth rate $\left(d^{-1}\right)$ for a copepod of biomass $=W_{c}(\mu g \mathrm{C})$. Potential growth of organisms in each size class was determined by multiplying $G$ for that size class by the carbon biomass $\left(W_{c}\right)$ and abundance of that size class. A gross growth efficiency of 0.3 was assumed to convert potential growth rate to potential grazing, and total potential grazing was the sum of potential grazing within all size classes. A carbon-to-chl a ratio of $62 \mu \mathrm{g} \mu^{-1}$ (Valiela 1995) was used in calculations of the fraction of phytoplankton biomass grazed per day.

Statistical analysis. All statistical analyses were conducted using SAS statistical software (SAS 1990). Analyses of variance were conducted on nutrient. metabolism, and macrozooplankton data averaged over the entire experiment and for periods before the nutrient pulse ('pre-pulse' = Days 2 to 13), during and immediately after the pulse ('pulse' = Days 14 to 18) and after the pulse ('post-pulse' = Days 19 to 28). For chl $a$, copepod abundance, and potential grazing ANOVA was also conducted on each of the sampling dates. Multivariate repeated-measures analysis of variance (Gurevitch \& Chester 1986, Green 1993) was used to assess and compare changes in copepod abundance and potential grazing and nutrient concentration over time among mixing treatments. Stepwise multiple regression of accessory pigments against chl a was used both to identify the presence of various phytoplankton groups and to partition the fraction of total chl a (i.e. phytoplankton biomass) attributable to each (Gieskes et al. 1988, 'Tester et al. 1995). For each of the days, differences in the fraction of pigment attributable to chl a among treatments were also assessed with ANOVA. Prior to ANOVA, the arcsine transformation (Sokal \& Rohlf 1981) was applied to insure normality of ratio variables including the fraction of chl a potentially grazed and relative contributions of accessory pigments to chl a. Linear regression was also used to explore relationships between average macrozooplankton abundance and mixing variables. Unless otherwise noted, statistical significance for ANOVA was assessed at the $p=0.05$ level.

\section{RESULTS}

\section{Nutrients and chl a}

No significant differences in nutrient concentrations among mixing levels were evident in data averaged over 
either pre- or post-pulse periods (Fig. 3). Average prepulse concentrations were $2.1 \mu \mathrm{M}$ for DIN, $0.014 \mu \mathrm{M}$ for $\mathrm{PO}_{4}$, and $42 \mu \mathrm{M}$ for Si. Average post-pulse concentrations were $1.1 \mu \mathrm{M}$ for DIN, $0.005 \mu \mathrm{M}$ for $\mathrm{PO}_{4}$, and $9.0 \mu \mathrm{M}$ for Si. DIN and Si concentrations decreased significantly in all 3 treatments between the first and second sampling (Days 1 and 3). Although data averaged over each period were not different among treatments, $\mathrm{PO}_{4}$ concentrations in the second sampling after the pulse were significantly greater in the low mixing treatment than in the high mixing treatment and greater in the high treatment than the intermediate treatment.
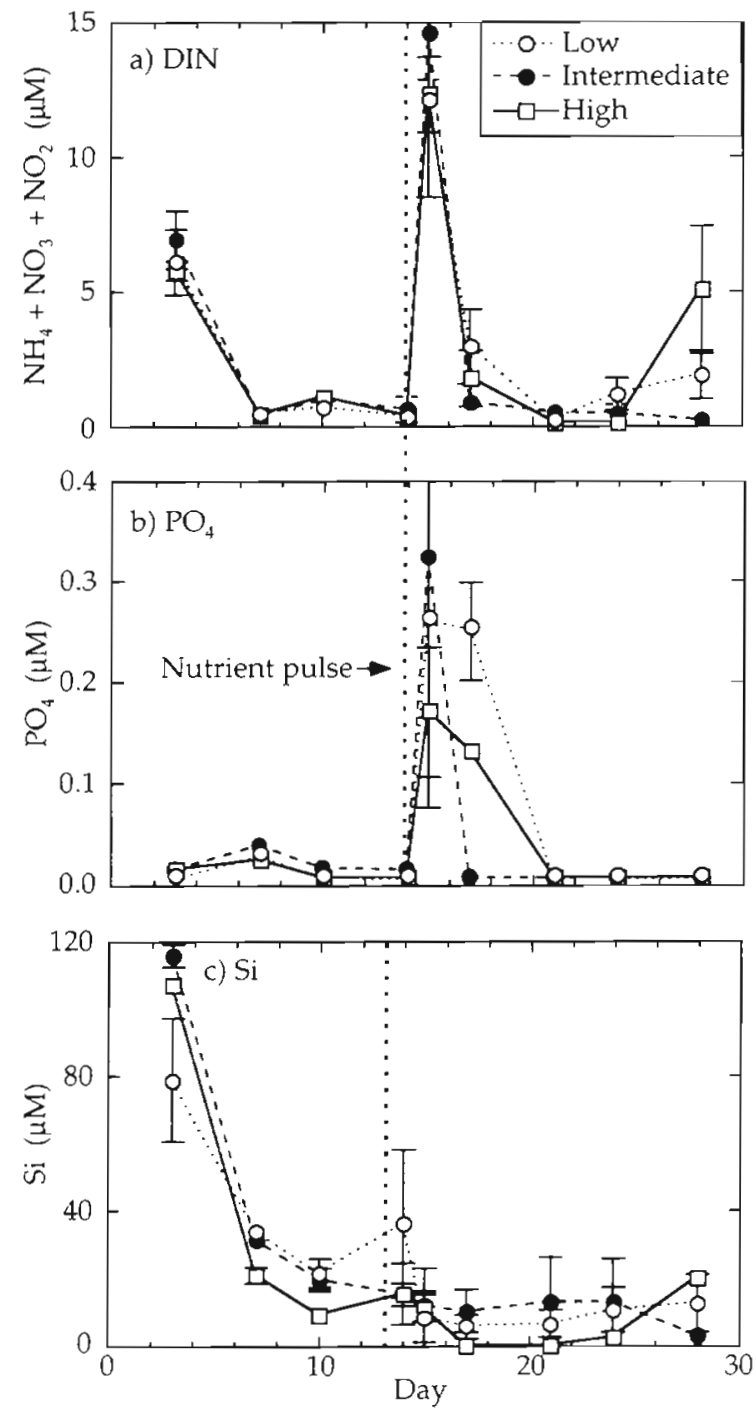

Fig. 3. Dynamics of dissolved inorganic nitrogen $\left(\mathrm{DIN}=\mathrm{NH}_{4}\right.$ $\left.+\mathrm{NO}_{3}+\mathrm{NO}_{2}\right)$, phosphate $\left(\mathrm{PO}_{4}\right)$, and dissolved silicate ( $\mathrm{Si}$ ) in the 3 mixing treatments (low, intermediate, high). As indicated a pulse of DIN and $\mathrm{PO}_{4}$ was delivered on Day 14 to raise concentrations 1030 and $1.6 \mu \mathrm{M}$ respectively. Values are mean \pm SE. Error bars are not included when they are smaller than the width of the symbols
The general pattern of chl a abundance during the pre-pulse period was remarkably similar among treatments (Fig. 4a). An initial phytoplankton bloom peaked on Day 5 in all treatments and then declined steadily until the nutrient pulse. The nutrient pulse delivered on Day 14 induced a bloom in all 3 mixing levels, but both the pattern and overall magnitude of the response were distinct among treatments. Values in the low mixing treatment peaked on Day 16 and then declined relatively rapidly. Phytoplankton in the high mixing treatment sustained a long-lasting bloom, which did not begin to decline until Day 24 . Chl $a$ in the intermediate mixing level exhibited the smallest response to the nutrient pulse. ANOVA performed for data on each day of the post-pulse period identified statistically significant differences among treatments on most days. Data averaged over the post-pulse period revealed a positive relationship between mixing and water column chl $a_{1}$ with significant differences evident between the low and high treatment levels. When data were averaged over the experiment as a whole, the high mixing treatment
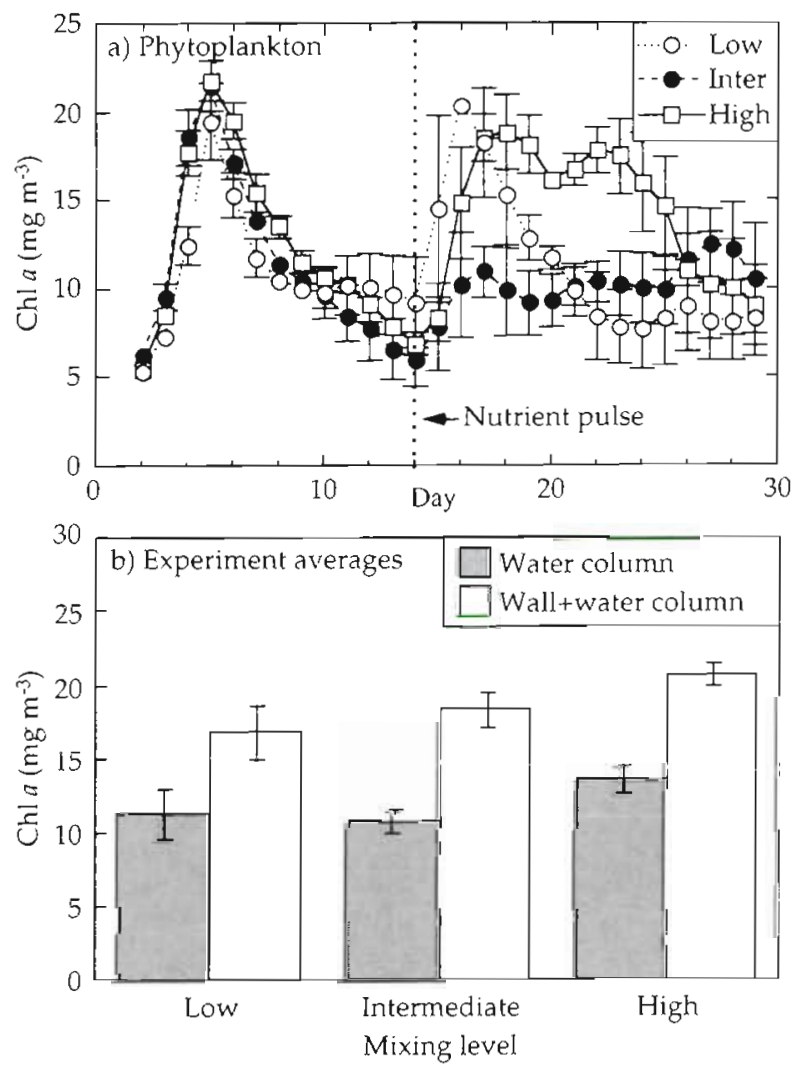

Fig. 4. Chlorophyll a concentrations. (a) Water column chlorophyll a dynamics in the 3 mixing treatments (low, intermediate, high) and (b) average water column and water column + wall periphyton chlorophyll a for the experiment as a whole. Values are mean $\pm \mathrm{SE}$ 
had higher water column chl $a$, however, differences among the treatments were not statistically significant (Fig. 4b).

Although tank walls were cleaned on a weekly basis, significant quantities of periphyton chl a were evident for all 3 mixing treatments on both of the days (Days 10 and 17) that samples were taken. The average wall periphyton chl a for the 2 samples taken was lowest in the low mixing, but differences among treatments were small and non-significant. Because periphyton samples were collected immediately prior to wall cleaning, the numbers generated provide an exaggerated estimate of average periphyton chl a. Averaged over the experiment as a whole, the sum of water column plus wall chl a increased with increased mixing, however, these differences were not statistically significant (Fig. 4b).

\section{Accessory pigments and phytoplankton composition}

Stepwise multiple regression of the 6 characteristic accessory pigments against phytoplankton chl a for pooled data from all samples collected indicated that only fucoxanthin, zeaxanthin, and alloxanthin contributed significantly to chl a concentration. The fact that the accessory pigments lutein, peridinin, and violaxanthin were not identified as contributing significantly to chl a indicates that chlorophytes, peridinincontaining dinoflagellates, and prasinophytes were not present in significant quantities in our mesocosms (Rowan 1989). For the 3 pigments identified as contributing significantly to total chl $a$, fucoxanthin is characteristic for the presence of diatoms, zeaxanthin is characteristic for cyanobacteria, and alloxanthin is characteristic for cryptophytes (Rowan 1989). It is possible that non-peridinin-containing dinoflagellates were also present.

The $y$-intercept for the regression of accessory pigments against chl a can be thought of as chl a which is unaccounted for by the pigments analyzed. Since the initial regression on these 3 pigments resulted in a negative and non-significant $y$-intercept, the final regression was conducted specifying a $y$-intercept of 0 . This final regression equation yielded the following relationship: chl $a=2.15$ [fucoxanthin] + 2.80[zeaxanthin] +4.37 [alloxanthin], with $r^{2}=0.99$ and $p$-values for significance of coefficients $=0.00,0.00$, and 0.02 respectively. These regression coefficients were then multiplied by accessory pigment concentrations in each sample to derive estimates of the contribution of these pigments to total water column chl a. The relative contribution of accessory pigment to chl a was then calculated by dividing these numbers by the concentration of chl a in each sample (Fig. 5).
ANOVA indicated that the relative contributions of accessory pigments to total chl a changed over time and exhibited small differences among treatments. In the initial samples taken on the first day of the experiment, zeaxanthin (cyanobacteria) accounted for the majority of chl a in all treatments, and there were no significant differences in the relative contribution of any of the pigments among mixing treatments. Values on Day 28 were very similar to values on Day 14, and repeated measures analysis indicated no significant changes between these sampling days. Data from these 2 samples were therefore pooled to generate a single 'mixing-adapted' sample (Fig. 5b). Between initial and mixing-adapted samples, the relative contribution of fucoxanthin (diatoms) increased significantly in all 3 treatments, and this increase in fucoxanthin was accompanied by a significant decreases in the relative contributions of both zeaxanthin (cyanobacteria) and alloxanthin (cryptophytes). In the mixingadapted sample, the contribution of fucoxanthin and alloxanthin increased with mixing while the contribu-

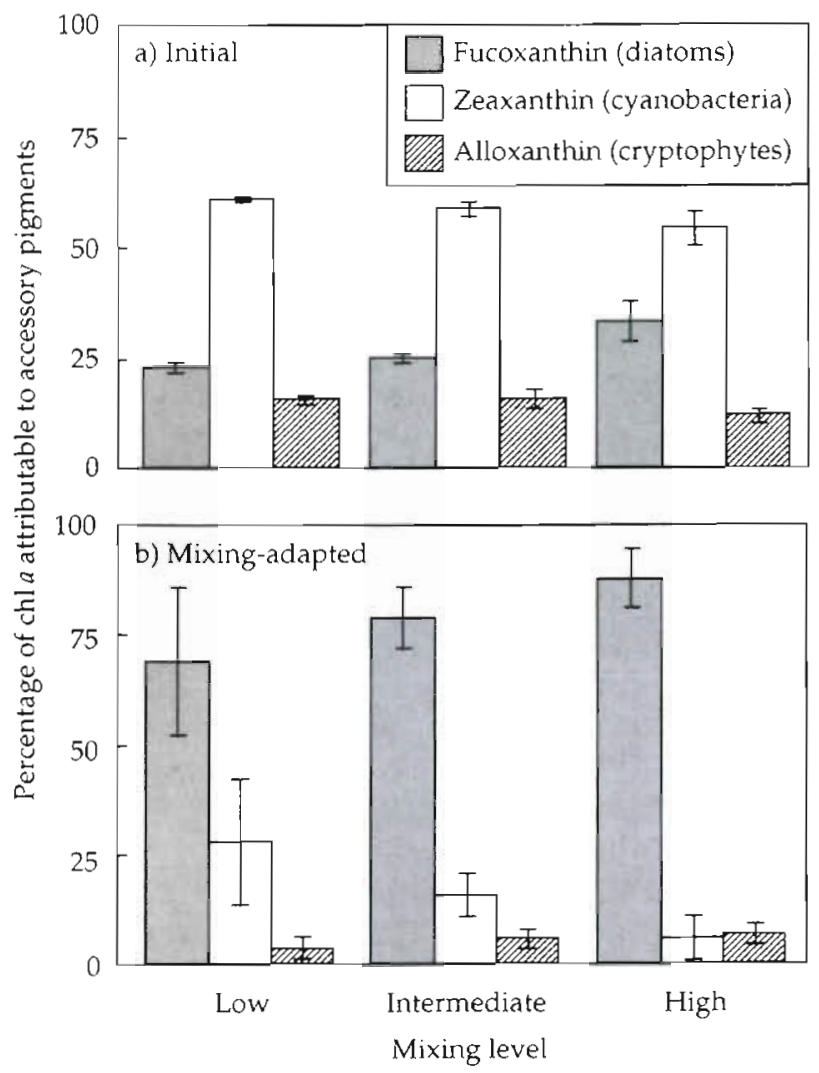

Fig. 5. Relative contributions of accessory pigments to water column chlorophyll $a$ in (a) initial and (b) mixing-adapted samples. Bars represent the fraction of water column chlorophyll a attributable to the characteristic pigments based on multiple linear regression. Planktonic groups associated with these pigments are noted in parentheses 

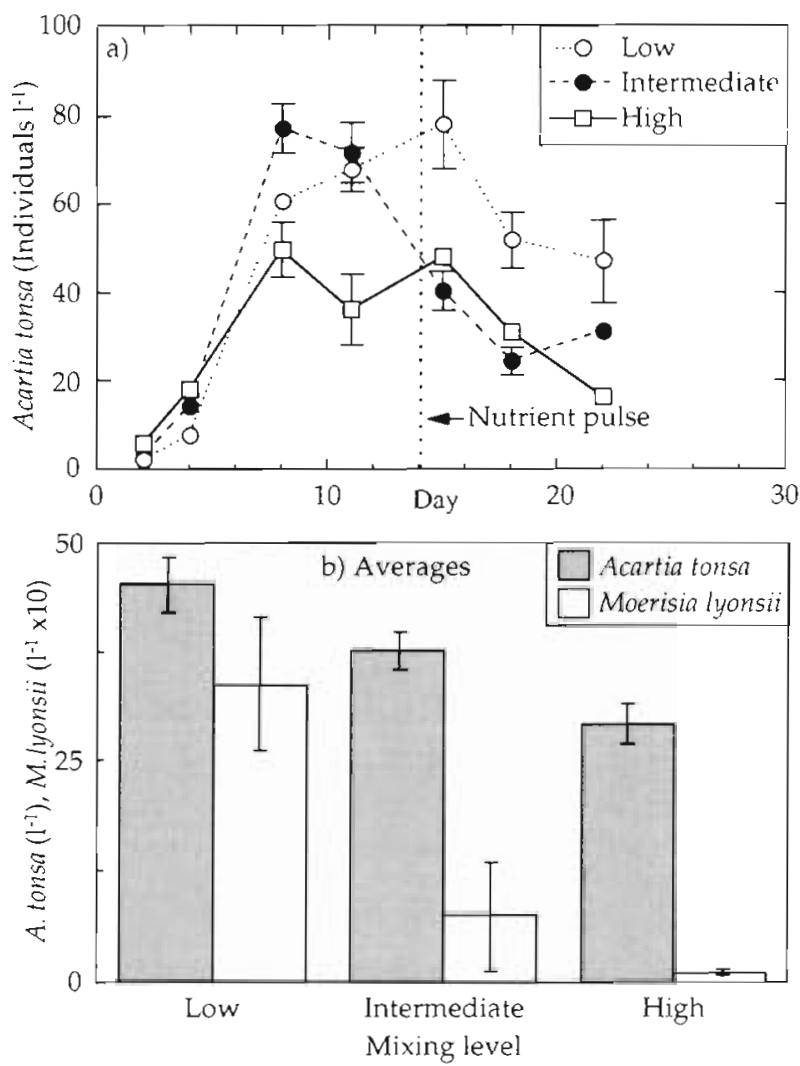

Fig. 6. (a) Copepod Acartia tonsa abundance on each sampling day in low, intermediate and high mixing treatments and (b) average copepod and gelatinous zooplankton Moerisia lyonsii abundance for all sampling days. Values are mean \pm SE. Error bars are not included when they are smaller than the width of the symbols

tion of zeaxanthin decreased with increased mixing (Fig. 5b). Zeaxanthin concentration was only significantly greater than zero in the low mixing treatment, and alloxanthin concentration was only significantly different from zero in the high mixing treatment.

\section{Zooplankton}

A single species of copepod, Acartia tonsa, dominated throughout the experiment. The abundance of juveniles was roughly 10 times greater than the abundance of adults. In all mixing levels the abundance of adults and juveniles exhibited significant increases between Day 2 (first sampling) and Day 8 (3rd sampling), with the adult count increasing from an average of 0.4 to 5.1 individuals $\mathrm{l}^{-1}$ and juveniles increasing from 2.9 to $57.4 \mathrm{l}^{-1}$. Trends were similar for adults and juveniles, and total copepod abundance therefore provides a reasonable measure of overall pattern. Significant differences in total abundance among mixing lev- els were evident on each of the 7 sampling days and distinct patterns of change over time among treatments were also evident (Fig 6a). Intermediate and high mixing levels achieved peak abundance on Day 8 , whereas the low mixing level did not peak until Day 15. Data averaged over the entire experiment indicate a decrease in abundance with increasing mixing (Fig. 6b), with statistically significant differences evident between high and low mixing for both juveniles and total counts.

Statistical differences in calculated potential copepod grazing rates among treatments closely paralleled differences in total copepod abundance on each sampling date (Fig. 6a). As with abundance, statistical differences among the treatments were evident on each of the 7 dates that copepod samples were taken. For the experiment as a whole, average potential copepod grazing rates were $36.2,30.2$, and $23.7 \mu \mathrm{g} \mathrm{C} \mathrm{l} \mathrm{l}^{-1} \mathrm{~d}^{-1}$ in low, intermediate, and high treatments respectively. Differences in these experiment averages were statistically significant between high and low treatment levels.

To estimate the effect of grazing by copepods, we also calculated the potential percentage of phytoplankton grazed per day, and the percentage of $G P P$ grazed. The relative rank of both the percentage of phytoplankton grazed per day and the percentage of GPP grazed were the same as the rank of copepod abundance for all but 1 sampling date (different days for the 2 percentages). The fraction of phytoplankton biomass potentially grazed per day achieved a maximum value of $27 \%$ during peak copepod abundance in the low mixing treatment mesocosms; however, averaged over the experiment as a whole, the phytoplankton biomass potentially grazed was 6.3, 5.7, and $3.4 \% \mathrm{~d}^{-1}$ in low, intermediate, and high mixing treatments respectively. In contrast to copepod abundance, the percentage potentially grazed per day was only significantly different among treatments on 3 of the 7 sampling dates, and was not significantly different for data averaged over the experiment as a whole. The fraction of GPP potentially grazed was only $2.0,1.8$, and $1.3 \%$ in low, intermediate, and high mixing treatments respectively, and these values were also not statistically different from each other.

Data for the gelatinous zooplankton Moerisia lyonsii were averaged over the 2 dates on which samples were collected (Days 25 and 28). As with Acartia tonsa, abundance of $M$. lyonsii decreased with increased mixing (Fig. 6b). Although the abundance of $M$. Iyonsii in the intermediate mixing level was not significantly different from abundance in the high mixing level, the low mixing level had a significantly greater abundance of $M$. Iyonsii than either high or intermediate treatments. In an effort to determine specifically how zoo- 
plankton were related to mixing, the average abundances of $A$. tonsa and $M$. lyonsii were regressed against vertical eddy diffusivity $\left(K_{z}\right)$ and turbulent energy dissipation $(\varepsilon)$ in both linear and log transformed forms $(3$ levels $\times 3$ replicates $=9$ data points for each regression). Strong and significant relationships were evident for regressions of the natural log of abundance against the natural $\log$ of $\varepsilon$ (these regressions produced the largest $\mathrm{r}^{2}$ and lowest $\mathrm{p}$-values). The relationship for $M$. lyonsii was: $\ln (M$. lyonsii $)=-0.68 \ln (\mathrm{e})+$ $4.0\left(\mathrm{r}^{2}=0.71\right.$, p slope $<0.01, \mathrm{p}$ intercept $\left.<0.01\right)$. The relationship for $A$. tonsa was: $\ln (A$. tonsa $)=-0.08 \ln (\mathrm{e})$ $+3.4\left(\mathrm{r}^{2}=0.76\right.$, $\mathrm{p}$ slope $<0.01$, $\mathrm{p}$ intercept $\left.<0.01\right)$.

\section{Community and ecosystem productivity and respiration}

Data on primary productivity and respiration in the plankton and periphyton communities were averaged over the 4 sampling dates. It is important to recognize that the incubation chambers in which plankton and wall community metabolism were measured contained identical internal mixing regimes during rate measurements. Differences in the metabolic activity among treatments therefore represent the effect of prior mixing history on productivity and respiration rather than the direct and immediate in situ effects of mixing on productivity and respiration. In the plankton community, average primary productivity and respiration were both substantially higher in the high mixing treatment than in either intermediate or low mixing treatments (Fig. 7a). However, variability between replicates was also high, such that no significant differences among treatments were detectable. Average net primary productivity in the periphyton community was also substantially higher in the high mixing treatment than in intermediate or low regimes (Fig 7b), but again, due to high variability among replicates, differences were not statistically significant. No pattern of difference among mixing levels was evident for periphyton community respiration (Fig. 7b).

Patterns in whole-ecosystem net primary productivity $(N P P)$ and respiration $(R)$ were remarkably similar among treatments (Fig. $8 a, b$ ), and ANOVA revealed no statistical differences for data averaged over the pre-pulse, pulse, or post-pulse periods. ANOVA conducted on data averaged over the entire experiment also did not reveal statistical differences among treatments. There was, however, a slight trend of increase in magnitude of both $N P P$ and $R$ with increased mixing (Fig. 8c).

Regression analysis revealed a positive overall relationship between NPP and respiration (Fig. 9a). Since the $y$-intercept for this regression was not significantly
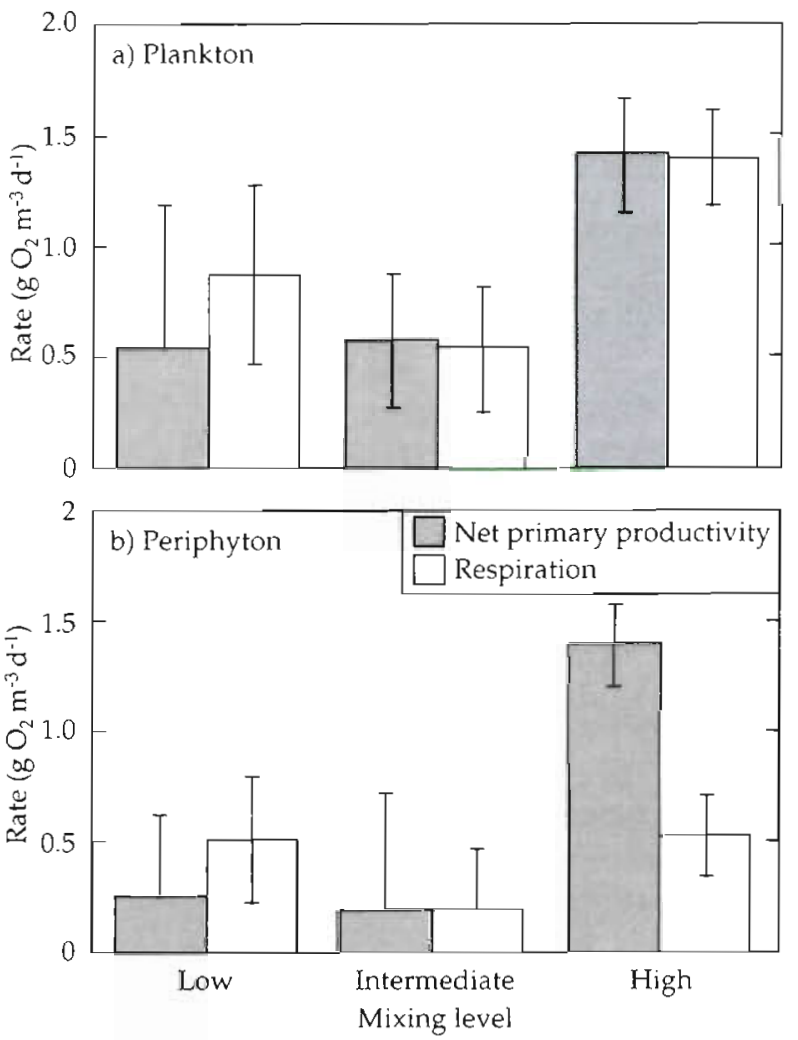

Fig. 7 Average net primary productivity and respiration in 3 mixing treatments of (a) plankton and (b) periphyton communities as determined in incubation tubes. Values for the periphyton community are expressed per unit of water column volume so as to be comparable with values for the plankton community. Values are mean $\pm \mathrm{SE}$

different from 0 , we chose to force a $y$-intercept of 0 . Regression on pooled data from all treatments $(n=118)$ resulted in the following equation: $N P P=1.3 R$, with $\mathrm{r}^{2}$ $=0.85$, and a $p$-value for the slope $<0.01$. $t$-tests were used to assess whether slopes differed among mixing treatments and it was found that they did not differ significantly. Regressions were also conducted to assess the relationship between GPP and water column chl a (Fig. 9b). A regression conducted on pooled data from all treatments resulted in the following equation: $G P P$ $=0.22(\mathrm{chl} \mathrm{a})+3.6$, with $\mathrm{r}^{2}$ of 0.35 and $\mathrm{p}$-values for slope $<0.01$ and intercept $<0.01$. Slopes and $y$-intercepts for the regression of GPP versus chl a also did not differ significantly among the treatments.

\section{DISCUSSION}

\section{Mixing environment}

Although we used 7 variables to characterize mixing (Table 2), a simplifying distinction can be drawn 

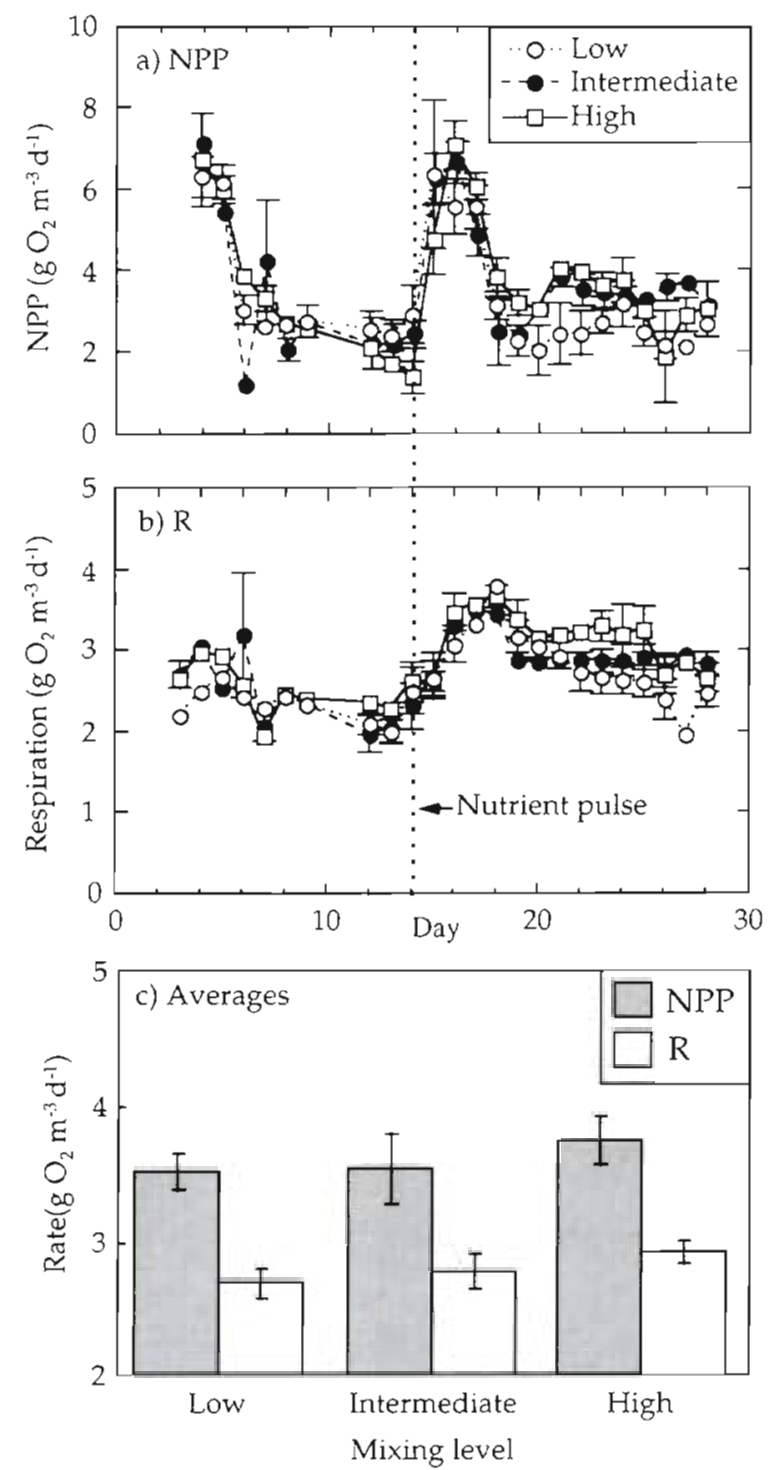

Fig. 8. Dynamics in whole-ecosystem (a) net primary productivity (NPP) and (b) respiration $(R)$, and $(c)$ average values for the entire experiment in 3 mixing treatments. Values are mean \pm SE. Error bars are not included when they are smaller than the width of the symbols

between mixing parameters that describe the smallscale environment around organisms and those that describe larger-scale vertical mixing in the water column (Estrada \& Berdalet 1997, Sanford 1997). Key parameters for characterizing large-scale vertical mixing include mixing time $\left(T_{\mathrm{m}}\right)$ and vertical eddy diffusivity $\left(K_{z}\right)$, which for a constant depth $(z)$ are inversely related $\left(T_{\mathrm{m}}=z^{2} / 2 K_{2}\right)$. The turbulent energy dissipation rate $(\varepsilon)$, on the other hand, provides a good measure of the small-scale mixing environment. Even in our low mixing treatment, vertical mixing was sufficient to prevent the formation of vertical gradients in dissolved
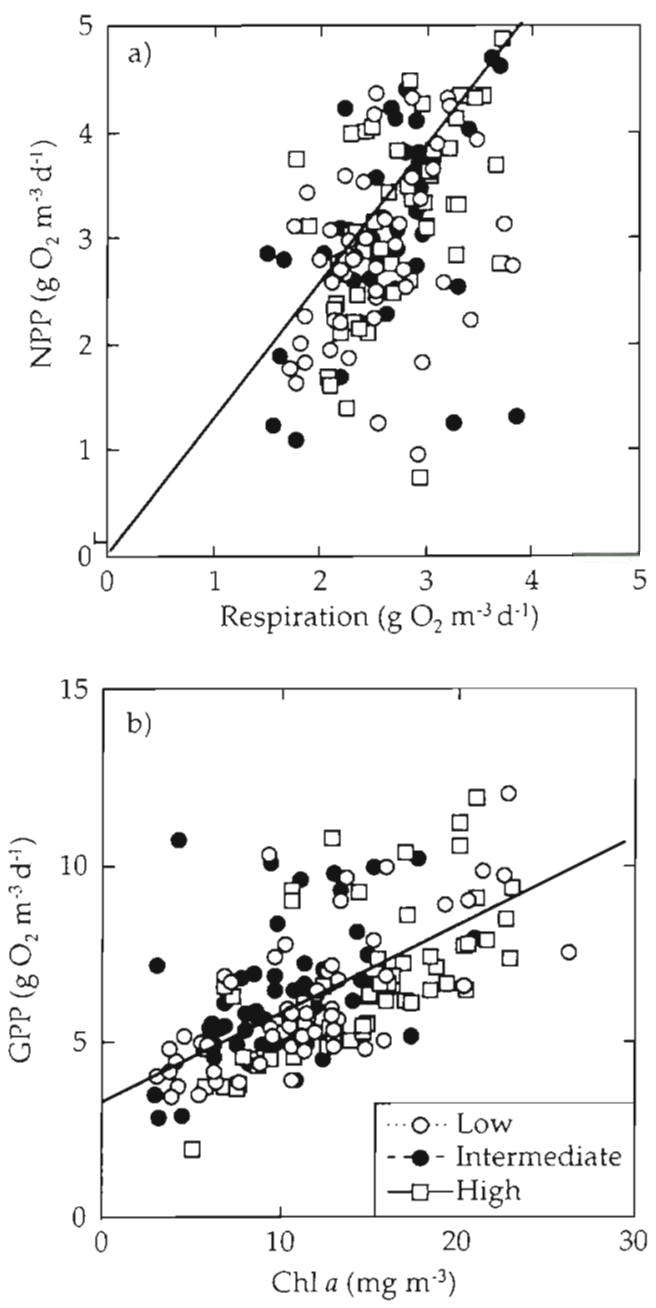

Fig. 9. Relationships between (a) net primary productivity and respiration and (b) gross primary productivity $(G P P)$ and chlorophyll $a$ in the 3 mixing treatments. Each data point represents $1 \mathrm{~d}$ of the experiment in 1 mesocosm. Slopes for over

all regression lines were both significant at $p<0.01$

oxygen. Photoadaptation of phytoplankton in response to mixing only occurs when the time scale necessary for physiological change is shorter than the time scale of changes in the light climate induced by mixing (Cullen \& Lewis 1988). Given that vertical mixing was relatively rapid even in the low mixing treatment (Table 2), differences among treatments in the plankton community are likely to be primarily a result of small- rather than large-scale mixing. However, to some extent the delivery of the nutrient pulse can be viewed as a simulation of nutrient replenishment that occurs as a result of large-scale vertical mixing events such as storms. The mixing environment experienced by algae living attached to the wall and on the sediment surface is distinct from the planktonic environment. For these stationary organisms, water velocity is 
a key factor determining access to resources present in the water column (Odum \& Hoskin 1957).

\section{Mixing effects on nutrient dynamics}

Previous experiments have found that nutrient uptake rates tend to increase with flow rate (Riber \& Wetzel 1987) and with turbulent mixing (Pasciak \& Gavis 1975: Table 1), or conversely that nutrient concentrations in the water column increase with decreasing mixing (Oviatt 1981). In our experiment, the only significant difference in nutrient concentration among treatments was observed on the second sample taken after the nutrient pulse was delivered. At that time phosphate concentration was highest in the low mixed system, and this pattern is consistent with the positive relationship between nutrient removal and mixing found by others. When the experiment is viewed as a whole, however, the outstanding feature of the inorganic nutrient data is the remarkable similarity in trend among treatments (Fig. 3). This similarity indicates that mixing effects were secondary to other processes controlling nutrient dynamics.

Although dissolved silica concentrations were well above typical half-saturation concentrations (e.g. Azam \& Chisholm 1976, Paasche 1980) throughout the experiment, nitrogen and phosphorus concentrations were at or below typical half-saturation constants (Eppley et al. 1969, Furnas et al. 1976, Goldman \& Glibert 1983) during both pre-and post-pulse periods in all 3 mixing treatments. This implies that the mesocosms were almost certainly nutrient limited for most of the experiment. It is quite possible that more substantial differences in nutrient concentrations would have been observed if the experiment had been conducted under more eutrophic conditions. However, the similarity in dynamics under low nutrient conditions indicates that within the range of turbulent mixing experienced in our treatments, elevated mixing evidently did not provide producers with a dramatically increased ability to extract nutrients from a nutrient depauperate water column.

\section{Mixing effects on chl a}

Previous studies have found a positive relationship between turbulence and chl a (Estrada et al. 1987; Table 1). In our experiment, patterns in water column chl a dynamics were almost identical during the prepulse period (Fig. 4a). The significant increase in timeaveraged productivity with increasing mixing following the pulse is consistent with the concept that increased mixing augments phytoplankton access to nutrients (e.g. Pasciak \& Gavis 1975). However, this argument is rather weak in that the low mixing treatment responded rapidly to the pulse and with a magnitude that was initially equal to the response of the high mixing treatment (Fig. 4a). An alternative possibility is that the pattern observed following the pulse is more attributable to indirect effects of grazing. Indeed, copepod abundance and potential grazing during the post-pulse period were significantly higher in the low mixing treatment than in either the intermediate or high mixing treatments (Fig. 6), which were not different from each other. Higher grazing pressure would provide a plausible explanation for the rapid decline of chl $a$ in the low mixing treatment (Fig. 4a). As we discuss below, however, total potential copepod grazing rates were probably insufficient to completely account for the substantial differences in phytoplankton chl a among treatments.

Although differences were not statistically significant, the fact that average wall periphyton chl a was higher in the intermediate and high mixing treatments than in the low mixing treatment is at least consistent with the positive relationship between velocity and periphyton biomass found in streams (Whitford 1960, McIntire 1966). The increase in total chl a of phytoplankton plus wall periphyton chl a (Fig. $4 \mathrm{~b}$ ) is also consistent with a positive relationship between mixing and producer biomass. We did not measure benthic chl a in this experiment, but, data from a subsequent. experiment suggest that total benthic chl a was probably low relative to water column and wall chl $a$.

\section{Mixing effects on phytoplankton community composition}

Single species culture experiments indicate that different taxonomic groups of phytoplankton have different sensitivities to turbulence, with tolerances decreasing from green algae to cyanobacteria to diatoms to dinoflagellates (White 1976, Thomas \& Gibson 1990a). Theory and observation in nature also tend to link dinoflagellates with areas of lowest turbulence, but link diatoms with areas of greatest mixing energy (Margalef 1978, Estrada \& Berdalet 1997). In the mixing-adapted samples in our experiment, the relative abundance of diatoms and cryptophytes increased with turbulence while the relative abundance of cyanobacteria decreased with turbulence (Fig. 5b). One possible explanation for this pattern is that increased mixing may confer some sort of a direct advantage to diatoms in terms of access to nutrients or light (Eppley et al. 1978, Margalef 1979). An alternative possibility is that selective feeding on diatoms at low turbulence levels may occur as a result of differen- 
tial effects of turbulence on copepod feeding mode. Specifically, non-motile phytoplankton such as diatoms cannot be perceived with the mechanoreceptors that are used for ambush feeding, and consumption of these organisms therefore only occurs in suspension feeding mode (Saiz \& Kiørboe 1995). Previous studies demonstrate that the relative importance of ambush versus suspension feeding by Acartia tonsa increases with turbulent energy dissipation up to levels of $10^{-1} \mathrm{~cm}^{2} \mathrm{~s}^{-3}$ (Saiz \& Kiørboe 1995), a level between our intermediate and high mixing treatments. The observed increase in the relative abundance of diatoms with increased mixing is at least consistent with this shift in feeding mode.

Previous multispecies experiments indicate an increasing ratio of diatoms to flagellates with increasing mixing intensity (Estrada et al. 1987; Table 1). Our data are consistent with this finding; the increase in the relative abundance of diatoms in response to mixing was more substantial than the increase in the relative abundance of flagellated cryptophytes. In contrast to previous findings that blue-green algae are relatively insensitive to mixing (e.g. Thomas \& Gibson 1990a), chl a attributable to cyanobacteria was negatively related to turbulence. It is conceivable that differences in cyanobacteria may be connected with turbulence effects on nitrogen fixation (see Fogg 1.987. Howarth et al. 1993 for contrasting views); however, the similarity in nitrogen dynamics among treatments (Fig. 3a) provides little support for this. Overall, the accessory pigment data indicate modest compensatory shifts in phytoplankton species composition in response to mixing. It is noteworthy that the change in species composition over time was as dramatic as the differences that developed among treatments in response to the mixing treatments (Fig. 5a, b). We have no way of knowing if the substantial increase in diatoms and concomitant decrease in cyanobacteria and cryptophytes evident in all treatments between the initial and mixing-adapted samples was an artifact of enclosure or a natural successional trend. If it was an artifact then it may have limited the potential response of the system to the mixing treatments.

\section{Direct and indirect mixing effects on copepods}

The decrease in copepod abundance with increased mixing (Fig, 6) is consistent with the findings of a number of previous studies (Alcaraz et al. 1988; Table 1). Both direct and indirect effects of mixing might plausibly account for this negative relationship (Fig. 1). Indirect mixing effects that might account for such a pattern include a decrease in food supply and an increase in predation on copepods with increased mixing. In our experiment there is little evidence for either of these mechanisms. From the food perspective, Acartia tonsa is known to consume both heterotrophic protozoa and a variety of phytoplankton (Merrell 1996). The fact that A. tonsa differed significantly in abundance (Fig. 6a) well before differences were evident in chl a (Fig 4a) implies that differences in copepod abundance are probably not attributable to differences in the total biomass of phytoplankton as a food source. We did not collect data on heterotrophic protozoa, but Peters \& Gross (1994) found that protozoa growth is enhanced by turbulence. This suggests that the decrease in copepod abundance with increased mixing in our study is also not attributable to differences in heterotrophic protozoa as a food source. The mesocosms were free of significant abundance of known predators on copepods until the last week of the experiment when the gelatinous zooplankton Moerisia lyonsii became abundant. Since $M$. lyonsii abundance also decreased with increasing mixing (Fig. 6b), it is unlikely that A. tonsa was regulated by predation. Thus it appears that these indirect mixing effects were not responsible for the negative relationship between copepods and turbulence.

Previous studies indicate that mixing directly affects several aspects of copepod physiology and behavior (Table 1). For instance, although turbulence increases contact rates between predator and prey, increased contact does not necessarily result in increased consumption (Shimeta \& Jumars 1991); high turbulence intensities can advect food out of reach of copepods before they have time to react (Kiørboe \& Saiz 1995). Indeed, a decline in the clearance rate of Acartia tonsa has been observed at turbulent energy dissipation rates as low as $10^{-1} \mathrm{~cm}^{2} \mathrm{~s}^{-3}$ (Saiz \& Kiørboe 1995), a level between our intermediate and high mixing treatments. Although copepods may be able to habituate to increases in turbulence (Hwang et al. 1994), turbulence can increase metabolic activity by mechanically stimulating escape response reactions (Saiz \& Alcaraz 1992a, Saiz et al. 1992).

Turbulence is inherently variable so that organisms typically experience a wide range of turbulence in any habitat. Nevertheless, average turbulent energy dissipation in our intermediate mixing level was towards the upper end of the range of values under which Acartia tonsa is typically found in nature, with turbulence in the high mixing treatment about 10 times greater than in typical habitat (Saiz \& Kiørboe 1995), so the negative relationship between copepod abundance and mixing is perhaps not surprising. It is worth noting, however, that even our high mixing treatment was well within the range of $\varepsilon$ and $K_{z}$ values found in other mesocosm experiments (Table 3 ). Exposing zooplankton to larger values of $\varepsilon$ and $K_{z}$ than they experj- 
ence in their native habitat (Sonntag \& Parsons 1979, Mann \& Lazier 1996) may therefore be an important source of unrealistic behavior in mesocosms.

To estimate the potential effect of variations in copepod abundance on phytoplankton biomass and primary productivity, we estimated feeding with an empirical model that considers grazing as a function of copepod size and temperature (Hirst \& Sheader 1997) Since it has been demonstrated that Acartia tonsa feeding rates are affected by turbulence and prey concentration (Saiz et al. 1992, Saiz \& Kiørboe 1995), the model we used is an over-simplification, but a comprehensive model that includes mixing has yet to be developed. Our calculations indicate that during peak copepod abundance potential grazing removed as much as $27 \%$ of phytoplankton standing stock per day; however, over the experiment as a whole potential grazing removed an average of only about $5 \%$ of the phytoplankton standing stock per day. Overall, the percentage of phytoplankton standing stock potentially consumed per day varied by only $2.9 \%$ between the low mixing and high mixing systems. The potential effect of grazing on GPP was even smaller, with an average potential consumption by grazing for the experiment as a whole of less than $2 \%$, and a range between high and low mixing of $0.7 \%$. These low rates may help explain why differences in zooplankton abundance among treatments were accompanied by much smaller differences in chl a. However, if we assume that selective grazing on diatoms was enhanced in the low mixing levels, this level of grazing may have been sufficient to contribute to the differences observed in phytoplankton community composition.

\section{Scaling zooplankton abundance to turbulence}

Separate experiments conducted in the same mesocosm facility indicate that Moerisia lyonsii is an active predator on Acartia tonsa (J. E. Purcell unpubl.). The decrease in $A$. tonsa in all treatments following the appearance of $M$. lyonsii is therefore at least consistent with predation. Along this line of reasoning, one possible interpretation of the time-averaged data (Fig. 6b) is that $M$. lyonsii abundance was determined by copepod prey availability, and therefore $M$. lyonsii abundance was only an indirect function of mixing. A number of factors, including the fact that copepod biomass declined most dramatically in the high mixing treatment (which had the smallest abundance of $M$. lyonsii), lead us to conclude that, as with $A$. tonsa, the $M$. lyonsii abundance was determined by direct rather than indirect effects of mixing. Other studies have shown that gelatinous zooplankton tend to be ex-

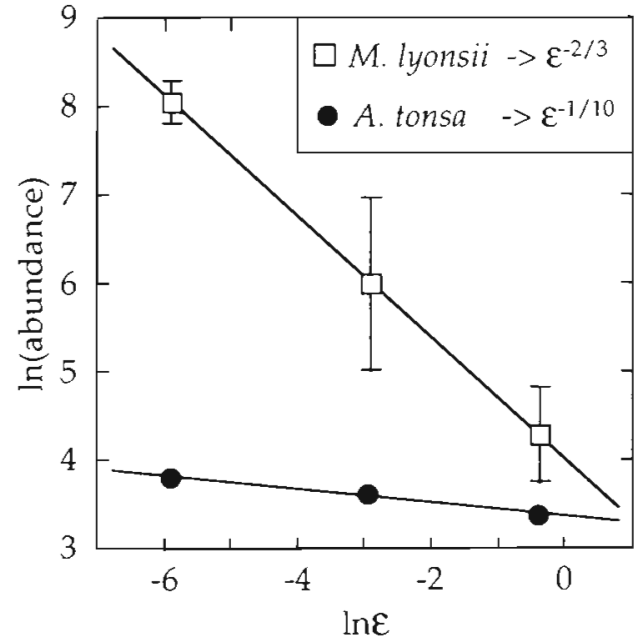

Fig. 10. Relationships between zooplankton abundance and the turbulent energy dissipation rate $(\varepsilon)$ in the 3 mixing treatments. Values are mean $\pm \mathrm{SE}$, error bars for Acartia tonsa abundance are smaller than the width of the symbols

tremely sensitive to damage by turbulence (Acuna et al. 1994).

The evidence that we have presented indicates that the abundance of both Acartia tonsa and Moerisia lyonsii is linked to the direct effects of mixing, and the careful characterization of mixing parameters in this experiment provides the opportunity to quantify this link. Theory suggests that behavior dynamics are likely to be associated with small-scale mixing, and the significant relationships evident in a linear regression of log transformed data indicate strong scaling relationships between turbulent energy dissipation and the average abundance of both copepods and gelatinous zooplankton (Fig. 10). The slopes of these log-log relationships indicate that $M$. lyonsii abundance scaled to $\varepsilon^{-2 / 3}$ while $A$. tonsa abundance scaled to $\varepsilon^{-1 / 10}$. It is possible and perhaps even probable that other slopes could have been obtained if the experiment had been of longer or shorter duration or if higher order predators had been included. Nevertheless, the facts that zooplankton abundance could be quantitatively related to mixing, that out of the 7 mixing parameters the abundances of 2 very different kinds of zooplankton were both most strongly related to turbulent energy dissipation, and that the different zooplankters exhibited different slopes are interesting and provocative pieces of information. These relationships imply that it may be possible to scale certain aspects of population and community dynamics as quantitative functions of mixing energy. That different organisms can apparently have quite distinct scaling coefficients indicates that under certain circumstances dramatic shifts in trophic dynamics might result from changes in turbu- 
lent energy input. We have no way of knowing how robust these relationships are. Further study is obviously warranted to determine if and under what conditions zooplankton abundance predictably scales to turbulent energy dissipation or to other mixing parameters.

\section{Community and ecosystem metabolism}

In contrast to the clear relationships for consumers, relationships between community and whole-ecosystem metabolism and mixing were weak. Average net primary productivity in plankton and periphyton communities was highest in the high mixing treatment (Fig. $7 \mathrm{a}, \mathrm{b}$ ), but variability among replicates was high and differences were not statistically significant. Patterns in whole-ecosystem primary productivity and respiration in the different mixing treatments were nearly identical (Fig. 8a, b). Regressions of NPP versus respiration and $G P P$ versus chl a were significant, however, slopes did not differ among treatments (Fig. 9). Lastly, as we have already indicated, grazing only had a very small potential effect on primary productivity. Theories of auxiliary energy subsidy (Margalef 1978, Nixon 1988, Mann 1992) notwithstanding, the only reasonable conclusion to draw from our experiment is that the manipulation of the small-scale mixing environment had a negligible effect on ecosystem metabolism. The dramatic and similar response to the nutrient pulse in the different treatments indicates that ecosystem metabolism was apparently driven by nutrients and perhaps light input that were held constant among the treatments.

\section{Conclusions}

Our objective in this experiment was to simultaneously explore the effects of mixing on population, community, and ecosystem level dynamics in shallow planktonic systems. We found that manipulation of the small-scale mixing environment induced substantial differences in zooplankton abundance; modest differences in phytoplankton biomass and taxonomic composition; yet smaller differences in the metabolism of water column, wall, and benthic communities; and essentially no differences in total system metabolism or nutrient dynamics. We conclude from this that compensatory interactions at population and community levels damped the effects of small-scale mixing energy on overall ecosystem function. Although we believe that similar dynamics may often occur in nature, it is important to acknowledge that the limited range of conditions within our experiment no doubt affected the results observed. For instance, our experiment encompassed a wide range in mixing parameters (Table 2). but even the lowest mixing level treatment was well mixed in the sense that surfce to bottom gradients were prevented from forming. Systems that are significantly under-mixed would likely exhibit more dramatic differences. Different ecological responses to turbulence might occur under a variety of scenarios including more eutrophic conditions, more realistic simulation of the benthic boundary layer, biologically open systems which more realistically simulate advection, and inclusion of additional trophic levels or types of organisms such as fish or filter feeders. It is also possible that an experiment of sufficient duration to include several generations of macrozooplankton would have eventually resulted in closer coupling between these relatively large organisms and primary productivity. We speculate that the effects of mixing vary greatly with ecological context, and that under certain conditions mixing effects may well propagate up the ecological hierarchy to result in differences in ecosystem level behavior. On the one hand, this implies that ecosystem level concepts such as the auxiliary energy subsidy hypothesis (Margalef 1978, Nixon 1988, Mann 1992) are unlikely to be broadly generalizable. On the other hand it also implies that ecosystem level experiments provide an essential test of mixing effects elucidated in single and multispecies cultures.

Acknowledgements. We are indebted to Jenny Purcell for collecting and sharing Moerisia lyonsii data and to Mike Roman and Anne Gauzens for sharing Acartia tonsa data and providing valuable guidance in interpretation. Steve Suttles provided technical assistance in setting up the mixing systems. Chung-Chi Chen, Tim Goertemiller, Tom Wazniak, and Debbie Hinkle provided indispensable assistance in data collection and analysis. The work of J.P. was performed under appointment to the Graduate Fellowships for Global Change Program administered by Oak Ridge Associated Universities for the U.S. Department of Energy (DOE), Office of Health and Environmental Research, Atmospheric and Climate Research Division. Our research was funded by the Environmental Protection Agency (EPA) as part of University of Maryland's Multiscale Experimental Ecosystem Research Center (MEERC) at the University of Maryland's Center for Environmental Science (Grant number R819640). We thank Barbara Sullivan, Victor Kennedy, and 2 anonymous reviewers for helpful suggestions on improving the manuscript.

\section{LITERATURE CITED}

Acuna JL, Deibel D, Sooley S (1994) A simple device to transfer large and delicate planktonic organisms. Limnol Oceanogr 39:2001-2003

Alcaraz M (1997) Copepods under turbulence: grazing. behavior and metabolic rates. Sci Mar 61:177-195

Alcaraz M, Saiz E (1992) External energy and plankton: new 
insights on the role of small-scale turbulence on zooplankton ecology. In: Ros J, Prat N (eds) Homage to Ramon Margalef; or why there is such pleasure in studying nature. Oecol Aquat (Spec Issue), p 137-1.44

Alcaraz M, Saiz E, Calbet A (1994) Small-scale turbulence and zooplankton metabolism: effects of turbulence on heartbeat rates of planktonic crustaceans. Limnol Oceanogr 39:1465-1470

Alcaraz M, Saiz E، Marrasé C, Vaqué D (1988) Effects of turbulence on the development of phytoplankton biomass and copepod populations in marine microcosms. Mar Ecol Prog Ser 49:117-125

Azam F, Chısholm SW (1976) Silicic acid uptake and incorporation by natural marine phytoplankton populations. Limnol Oceanogr 21:427-435

Benson BB, Krause DJ (1984) The concentration and isotopic fractionation of oxygen dissolved in freshwater and seawater in equilibrium with the atmosphere. Limnol Oceanogr 29:620-632

Bloesch J, Bossard P, Buhrer H, Burgi HR, Uehlinger U (1988) Can results from limnocorral experiments be transferred to in situ conditions? Hydrobiologia 159:297-308

Boyd CM (1981) Microcosms and experimental planktonic food chains. In: Longhurst AR (ed) Analysis of marine ecosystems. Academic Press, New York, p 627-649

Brockmann U (1990) Pelagic mesocosms: II. Process studies. In: Lalli CM (ed) Enclosed experimental marine ecosystems: a review and recommendations. Springer-Verlag, New York, p 81-108

Carritt DE, Carpenter JH (1966) Comparison and evaluation of currently employed modifications of the Winkler method for determining dissolved oxygen in seawater: a NASCO report. J Mar Res 24:286-318

Chen CC, Petersen JE, Kemp WM (1997) Spatial and temporal scaling of periphyton growth on walls of estuarine mesocosms. Mar Ecol Prog Ser 155:1-15

Cullen JJ, Lewis MR (1988) The kinetics of algal photoadaptation in the context of vertical mixing. J Plankton Res 10: $1039-1063$

Davies JM. Camble JC (1979) Experiments with large enclosed ecosystems. Phil Trans R Soc Lond (B) 286:523-544

Dempsey HP (1982) The effects of turbulence on three algae Skeletonema costatum, Gonyaulax tamarensis, Heterocapsa triquentra. S.B., Massachusetts Institute of Technology, Cambridge, MA

Doty MS, Oguri M (1958) Selected features of the isotopic carbon primary productivity technique. Rapp PV Réun CIESM Mediterr Monaco 144:47-55

Eppley R, Roger J, McCarthy J (1969) Half-saturation constants for uptake of nitrate and ammonia by marine phytoplankton. Limnol Oceanogr 14:912-920

Eppley RW, Koeller P, Wallace GTJ (1978) Stirring influences the phytoplankton species composition within enclosed columns of coastal sea water J Exp Mar Biol Ecol 32: $219-239$

Estrada M, Alcaraz M, Marrasé C (1987) Effects of turbulence on the composition of phytoplankton assemblages in marine microcosms. Mar Ecol Prog Ser 38:267-281

Estrada M, Berdalet E (1997) Phytoplankton in a turbulent world. Sci Mar 61:125-140

Estrada M. Marrasé C. Alcaraz M (1988) Phytoplankton response to intermittent stirring and nutrient addition in marine microcosms. Mar Ecol Prog Ser 48:225-234

Fogg GE (1987) Marine planktonic cyanobacteria. In: Fay P. Baalen CV (eds) The cyanobacteria. Elsevier, Amsterdam, p 393-414

Fogg GE, Than-Tun (1960) Interrelations of photosynthesis and assimilation of elementary nitrogen in a blue-green alga. Proc R Soc Lond B 153:117-127

Furnas M, Hitchcock G, Smayda T (1976) Nutrient-phytoplankton relationships in Narragansett Bay during the 1974 summer bloom. In: Wiley $M$ (ed) Estuarine processes Academic Press, New York, p 118-134

Gargett AE (1984) Vertical eddy diffusivity in the ocean interior. J Mar Res 42:359-395

Gargett AE, Sanford TB, Osborn TR (1979) Surface mixing layers in the Sargasso Sea. J Phys Oceanogr 9:1090-1111

Gervais F, Opitz D, Behrendt $H$ (1997) Influence of smatescale turbulence and large-scale mixing on phytoplankton primary production. Hydrobiologia 342/343:95-105

Gibson $\mathrm{CH}$, Thomas WH (1995) Effects of turbulence intermittency on growth inhibition of a red tide dinoflagellate, Gonyaulax polyedra Stein. J Geophys Res (C Oceans) 100 24841-24846

Gieskes WWC, Kraay GW, Nontji A, Setiapermana D Sutomo (1988) Monsoonal alternation of a mixed and a layered structure in the phytoplankton of the euphotic zone of the Banda Sea (Indonesia): a mathematical analysis of algal pigment fingerprints. Neth $J$ Sea Res 22 123-137

Goldman JC, Glibert PM (1983) Kinetics of inorganic nitrogen uptake by phytoplankton. In: Carpenter EJ, Capone DG (eds) Nitrogen in the marine environment. Academic Press, New York, p 233-274

Granata TC, Dickey TD (1991) The fluids mechanics of copepod feeding in a turbulent flow: a theoretical approach. Prog Oceanogr 26:243-261

Grant HL, Stewart RW, Moilliet A (1962) Turbulence spectra from a tidal channel. J Fluid Mech 12:41-263

Green RH (1993) Application of repeated measures designs in environmental impact and monitoring studies. Aust J Ecol $18: 81-98$

Gregg MC (1973) The temperature and saltiness of seawater can now be mapped centimeter by centimeter. Such mapping is needed to learn how the sea is so effectively stirred by the winds and the tides. Sci Am Feb:65-77

Gurevitch J. Chester STL (1986) Analysis of repeated experiments. Ecology 67:251-254

Gust G (1977) Turbulence and waves inside flexible-wall systems designed for biological studies. Mar Biol 42:47-53

Harbison GR (1992) Observations on the swimming and buoyancy of Cymbulia peroni (Gastropoda: Thecosomata) made from a submersible. J Mar Biol Assoc UK 72 $435-446$

Harrison PJ, Turpin DH (1982) The manipulation of physical chemical, and biological factors to select species from natural phytoplankton communities. In: Grice GD, Reeve MR (eds) Marine mesocosms. Springer-Verlag. New York, p 275-289

Heinle DR (1966) Production of a calanoid copepod, Acartia tonsa, in the Patuxent river estuary. Chesapeake Sci 7 $59-74$

Hess KW (1976) A three-dimensional numerical model of the estuarine circulation and salinity in Narragansett Bay Estuar Coast Mar Sci 4:325-338

Hill PS, Nowell ARM, Jumars PA (1992) Encounter rate by turbulent shear of particles similar in diameter to the Kolmogorov scale. J Mar Res 50:643-668

Hirst $A G$, Sheader $M$ (1997) Are in situ weight-specific growth rates body-size independent in marine planktonic copepods? A re-analysis of the global syntheses and a new empirical model. Mar Ecol Prog Ser 154:155-165

Howarth RW, Butler T, Lunde K, Swaney D, Chu CR (1993) Turbulence and planktonic nitrogen fixation: a mesocosm 
experiment. Limnol Oceanogr 38:1696-1711

Hwang JS, Costello JH, Strickler JR (1994) Copepod grazing in turbulent flow: elevated foraging behavior and habituation of escape responses. J Plankton Res 16:421-431

Ives AR, Foufopoulos J, Klopfer ED, Klug JL, Palmer TM (1996) Bottle or big-scale studies: how do we do ecology? Ecology 77:681-685

Kemp WA. Lewis MR, Cunningham FF, Stevenson JC, Boynton WR (1980) Microcosms, macrophytes, and hierarchies: environmental research in the Chesapeake Bay In: Giesy JP (ed) Microcosms in ecological research National Technical Information Service, Springfield, VA, p $911-936$

Kiørboe T. Saiz E (1995) Planktivorous feeding in calm and turbulent environments, with emphasis on copepods. Mar Ecol Prog Ser 122:135-145

Kromkamp J, Schanz F, Rijkeboer M, Berdalet E, Kim B, Gons HJ (1992) Influence of the mixing regime on algal photosynthetic performance in laboratory scale enclosures. Hydrobiologia 238:111-118

Lazier JRN, Mann KH (1989) Turbulence and the diffusive layers around small organisms. Deep-Sea Res 36 $1721-1733$

Levine ER, Kenyon KE (1975) The tidal energetics of Narragansett Bay. J Geophys Res (C Oceans) 80:1683-1688

Lueck RG, Osborn TR (1982) Dissipation measurements from the FRONTS-80 expedition. Department of Oceanography, University of British Columbia, Vancouver 38:183

Lundgren A (1985) Model ecosystems as a tool in freshwater and marine research. Arch Hydrobiol Suppl 70:157-197

Maclntyre S (1993) Vertical mixing in a shallow, eutrophic lake: possible consequences for the light climate of phytoplankton. Limnol Oceanogr 38:798-817

Mackenzie BR, Leggett WC (1991) Quantifying the contribution of small-scale turbulence to the encounter rates between larval fish and their zooplankton prey: effects of wind and tide. Mar Ecol Prog Ser 73:149-160

Madden CJ, Day JW (1992) Induced turbulence in rotating bottles affects phytoplankton productivity measurements in turbid waters. J Plankton Res 14:1171-1191

Mann KH (1992) Physical influences on biological processes: how important are they? S Afr J Mar Scl 12:107-121

Mann KH, Lazier JRN (1996) Dynamics of marine ecosystems: biological-physical interactions in the oceans, 2nd edn Blackwell Science, Inc, Cambridge, MA

Margalef R (1978) Life-forms of phytoplankton as survival alternatives in an unstable environment. Oceanol Acta 1: 493-509

Margalef R (1979) Functional morphology of organisms involved in red tides, as adapted to decaying turbulence. In: Taylor DL, Seliger $\mathrm{HH}$ (eds) Toxic dinoflagellate blooms. Elsevier/North Holland, New York, p 89-94

Marshall HG (1994) Chesapeake Bay phytoplankton: I. Composition. Proc Biol Soc Wash 107:573-585

McIntire CD (1966) Some effects of current velocity on periphyton communities in laboratory streams. Hydrobiologia $28.559-570$

Menze] DW (1977) Summary of experimental results: controlled ecosystem pollution experiment. Bull Mar Sci 27 $142-145$

Merrell JR (1996) Effects of spatial scaling and predation by copepods on microzooplankton population dynamics. Masters thesis, University of Maryland, College Park

Miller GR (1966) The flux of tictal energy out of the deep oceans. J Geophys Res (C Oceans) 71:2485-2489

Nixon SW (1988) Physical energy inputs and the comparative ecology of lake and marne ecosystems. Limnol Oceanogr
$33: 1005-1025$

Nixon SW, Alonso D, Pilson MEQ, Buckley BA (1980) Turbulent mixing in aquatic mesocosms. In: Giesy JP (ed) Microcosms in ecological research. National Technical Information Service, Springfield. VA, p 818-849

Nixon SW, Oviatt CA, Buckley BA (1979) Turbulent mixing in manne microcosms - some relative measures and ecological. consequences. In: Jacoff FS (ed) Advances in marine environmental research. Environmental Protection Agency. Narragansett, RI, p 382-409

Oakey NS, Elliott JA (1982) Dissipation within the surface mixed layer. J Phys Oceanogr 12:171-185

Odum EP (1984) The mesocosm. BioSci 34:558-562

Odum HT (1956) Primary production in flowing waters. Limnol Oceanogr 1:102-117

Odum HT (1967) Biological circuits and the marine systems of Texas. In: Olson TA, Burgess FJ (eds) Pollution and marine ecology. John Wiley and Sons, New York, p 99-157

Odum HT, Hoskin CM (1957) Metabolism of a laboratory stream microcosm. Florida Inst Mar Sci 4:115-133

Oviatt CA (1981) Effects of different mixing schedules on phytoplankton, zooplankton and nutrients in marine microcosms. Mar Ecol Prog Ser 4:57-67

Paasche E (1980) Silicon. In: Morris I (ed) The physiological ecology of phytoplankton. University of California Press, Berkeley, p 259-284

Parsons TR, Maita Y, Lalli CM (1984) A manual of chemical and biological methods for seawater analysis. Pergamon Press, New York

Pasciak WJ, Gavis J (1975) Transport limited nutrient uptake rates in Ditylum brightwellii. Limnol Oceanogr 20:604-61.7

Perez KT, Morrison GM, Lackie NF, Oviatt CA, Nixon SW, Buckley BA, Heltshe JF (1977) The importance of physical and biotic scaling to the experimental simulation of a coastal marine ecosystem. Helgoländer Meeresunters 30: $144-162$

Peters F, Gross T (1994) Increased grazing rates of microplankton in response to small-scale turbulence. Mar Ecol Prog Ser 115:299-307

Peters F, Redondo JM (1997) Turbulence generation and measurement: application to studies on plankton. Sci Mar 61: $205-228$

Petersen JE, Chen CC, Kemp WM (1997) Spatial scaling of aquatic primary productivity: experiments under nutrient and light-limited conditions. Ecology 78:2326-2338

Petersen JE, Cornwell J, Kemp WM (1n press) Implicit scalıng in the design of enclosed experimental aquatic ecosystems. Oikos

Redfield AC, Ketchum BH, Richards FA (1963) The influence of organisms on the composition of sea water. In: Hill NM (ed) The sea. Wiley-Interscience, New York, p 26-77

Reynolds CS (1994) The role of fluid motion in the dynamics of phytoplankton in lakes and rivers. In: Giller PS, HIldrew AG, Raffaelli DG (eds) Aquatic ecology. Scale, pattern and process. British Ecological Society. Blackwell Science, Oxford, p 141-187

Reynolds CS, Wiseman SW, Clarke MJO (1984) Growth- and loss-rate responses of phytoplankton to intermittent artificial mixing and theur potential application to the control of planktonic algal biomass. J Appl Ecol 21:11-39

Reynolds CS, Wiseman SW, Godfrey BM., Butterwick C (1983) Some effects of artificlal mixing on the dynamics of phytoplankton population in large limnetic enclosures. J Plankton Res 5:203-234

Riber HH, Wetzel RG (1987) Boundary-layer and internal diffusion effects on phosphorus fluxes in lake perphyton. Limnol Oceanogr 32:1181-1194 
Rothschild BJ, Osborn TR (1988) Small-scale turbulence and plankton contact rates. J Plankton Res 10:465-474

Rowan KS (1989) Photosynthetic pigments of algae. Cambridge University Press, New York

Saiz E, Alcaraz M (1991) Effects of small-scale turbulence on development time and growth of Acartia grani (Copepoda: Calanoida). J Plankton Res 13:873-883

Saiz E, Alcaraz M (1992a) Enhanced excretion rates induced by small-scale turbulence in Acartia (Copepoda: Calanoida). J Plankton Res 14:681-689

Saiz E, Alcaraz M (1992b) Free-swimming behavior of Acartia clausi (Copepoda: Calanoida) under turbulent water movement. Mar Ecol Prog Ser 80:229-236

Salz E, Alcaraz M. Paffenhöfer GA (1992) Effects of smallscale turbulence on feeding rate and gross-growth efficiency of three Acartia species (Copepoda: Calanoida). J Plankton Res 14:1085-1097

Saiz ES, Kiørboe T (1995) Predatory and suspension feeding of the copepod Acartia tonsa in turbulent environments. Mar Ecol Prog Ser 122:147-158

Sanford LP (1997) Turbulent mixing in experimental ecosystem studies. Mar Ecol Prog Ser 161:265-293

SAS (1990) Procedures guide, version 6, 3rd edn. SAS Institute Inc, Cary, $\mathrm{NC}$

Savidge G (1981) Studies of the effects of small-scale turbulence on phytoplankton. J Mar Biol Assoc UK 61:477-488

Shimeta J, Jumars PA (1991) Physical mechanisms and rates of particle capture by suspension feeders. Oceanogr Mar Biol Annu Rev 29:191-257

Shimeta J, Jumars PA, Lessard EJ (1995) Influences of turbulence on suspension feeding by planktonic protozoa: experiments in laminar shear fields. Limnol Oceanogr 40:845-859

Sokal RR, Rohlf FJ (1981) Biometry, 2nd edn. WH Freeman and Company, New York

Sonntag NC, Parsons TR (1979) Mixing and enclosed, $1300 \mathrm{~m}^{3}$ water column: effects on the planktonic food web. J Plankton Res 1:85-102

Steele JH, Farmer DM, Henderson EW (1977) Circulation and temperature structure in large marine enclosures. J Fish Res Bd Can 34:1095-1104

Sverdrup HU (1953) On conditions for the vernal blooming of phytoplankton. Rapp PV Reun CIESM Mediterr Monaco 18:287-295

Takahashi M, Whitney FA (1977) Temperature, salinity and

Editorial responsibility: Jennifer Purcell (Contributing Editor), Cambridge, Maryland, USA light penetration structures: controlled ecosystem pollution experiment. Bull Mar Sci 27:8-16

Tester PA, Geesey ME, Guo C, Paerl HW, Mllhe DF (1995) Evaluating phytoplankton dynamics in the Newport River estuary (North Carolina, USA) by HPLC-derived pigment profiles. Mar Ecol Prog Ser 124:237-245

Thomas WH, Gibson CH (1990a) Effects of small-scale turbulence on microalgae. J Appl Phycol 2:71-77

Thomas WH, Gibson CH (1990b) Quantified small-scale turbulence inhibits a red tide dinoflagellate, Gonyaulax polyedra Stein. Deep-Sea Res 37:1583-1593

Thomas WH, Gibson CH (1992) Effects of quantified smallscale turbulence on the dinoflagellate, Gymnodinium sanguineum (splendens): contrasts with Gonyaulax (Lingulodinium] polyedra, and the fishery implication. Deep-Sea Res 39:1429-1437

Thomas WH, Seibert DLR (1977) Effects of copper on the dominance and diversity of algae: controlled ecosystem pollution experiment. Bull Mar Sci 27:23-33

Valiela I (1995) Marine ecological processes, 2nd edn. Springer-Verlag, New York

Van Heukelem L, Lewitus AJ, Kana TM, Craft NE (1994) Improved separations of phytoplankton pigments using temperature-controlled high performance liquid chromatography. Mar Ecol Prog Ser 86:451-261

Verduin J (1969) Critique of research methods involving plastic bags in aquatic environments. Trans Am. Fish Soc 98: $335-336$

von Brockel K (1982) Sedimentation of phytoplankton cells within controlled experimental ecosystems following launching. and implications for further enclosure studies. In: Grice G, Reeve MD (eds) Marine mesocosms. SpringerVerlag, New York, p 251-259

Welch HC (1968) Use of modified diurnal curves for the measurement of metabolism in standing water. Limnol Oceanogr 13:679-687

Wesson JC, Gregg MC (1994) Mixing at Camarinal Sill in the Strait of Gibraltar. J Geophys Res (C Oceans) 99 $9847-9878$

White AW (1976) Growth inhibition caused by turbulence in the toxic marine dinoflagellate Gonyaulax excavata. J Fish Res Bd Can 33:2598-2602

Whitford LA (1960) The current effect and growth of freshwater algae. Trans Am Microsc Soc 79:302-309

Submitted: March 30, 1998; Accepted: June 18, 1998

Proofs received from author(s): August 20, 1998 